\title{
Novel electrospun polyvinylidene fluoride-graphene oxide-silver nanocomposite membranes with protein and bacterial antifouling characteristics
}

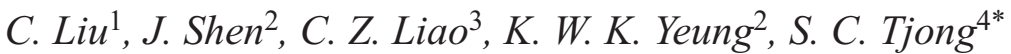 \\ ${ }^{1}$ College of Materials Science and Engineering, Shenzhen University, Shenzhen, China \\ ${ }^{2}$ Department of Orthopedics and Traumatology, Li Ka Shing Faculty of Medicine, The University of Hong Kong, \\ Hong Kong \\ ${ }^{3}$ Department of Materials Science and Engineering, Southern University of Science and Technology, Shenzhen, China \\ ${ }^{4}$ Department of Physics, City University of Hong Kong, Kowloon, Hong Kong
}

Received 29 September 2017; accepted in revised form 30 November 2017

\begin{abstract}
We developed and fabricated novel polyvinylidene fluoride (PVDF)-(0.5-2\%)Ag and PVDF-(0.5-2\%)Ag$1 \%$ graphene oxide (GO) nanocomposite membranes with antifouling properties through electrospinning. Silver nanoparticles (AgNPs) were in situ synthesized from silver nitrate precursor directly. The tensile properties, wetting, antifouling characteristics of pristine PVDF and its nanocomposite membranes were studied. Tensile tests showed that the addition of 0.52\% AgNPs to PVDF improves its elastic modulus and tensile strength markedly. A further increase in both tensile modulus and strength of PVDF were obtained by hybridizing AgNPs with 1\% GO. Water contact angle measurements revealed that the incorporation of AgNPs or AgNPs/GO nanofillers into PVDF decreases its degree of hydrophobicity. This led to the nanocomposite membranes having higher water flux permeation. In addition, AgNPs and AgNPs/GO fillers played a crucial role against protein and bacterial fouling of the resulting composite membranes. The antibacterial activities of electrospun nanocomposite membranes were assessed against Gram-negative Escherichia coli and Gram-positive Staphylococcus aureus. On the basis of water contact angle, water permeation flux and antifouling results, electrospun PVDF-2\% Ag-GO composite membrane was found to exhibit excellent filtration performance, protein antifouling and bactericidal activities. Thus such a fibrous nanocomposite is considered as a high-potential membrane for water purification and disinfection applications.
\end{abstract}

Keywords: nanocomposites, polymer membranes, polyvinylidene fluoride, wetting, fouling

\section{Introduction}

Water scarcity poses a threat and challenge to human society in all countries nowadays. Climate change, population growth, large scale development of agriculture and other industrial sector are the main causes of water shortages worldwide. In this respect, membrane-based water purification technologies play a critical role in addressing lack of water supply globally $[1,2]$. So the development of porous membranes for treating drinking and waste water is considered of technological importance. Different membrane methods have been used for various water treatment processes, including microfiltration, ultrafiltration, nanofiltration, reverse osmosis and forward osmosis. Synthetic polymer membranes such as poly(vinylidene fluoride) (PVDF), poly(sulfone), poly(arylene ether sulfone), polyethylene, and thin-film composite (TFC) polyamide membranes have been used widely for water purification processes [1-4]. The main limitation of such polymer membranes for water purification is fouling, which leads to a marked reduction of water flux over long term filtration [5]. Fouling in

*Corresponding author, e-mail: APTJONG@cityu.edu.hk

(C) BME-PT 
the membrane system can be classified into four categories including organic fouling, biofouling, inorganic fouling and particulate fouling [6]. Among them, organic fouling and biofouling constitute the major fouling on membranes. Organic fouling causes the blocking of the membrane pores by organic substances such as proteins, amino acids, carbohydrates, etc. [7-9]. Biofouling relates to the microbial adhesion and growth on the membrane surface, leading to the formation of a biofilm layer. The subsequent formation of extracellular polymeric substances (EPS) by microorganisms further stimulates microbial colonization of the membrane surface. Biofouling can be minimized by periodic washing with chlorinated disinfectants, but such a treatment often causes polymer membrane degradation and failure [10]. Furthermore, the release of biocides to the environment can lead to water contamination and pollution.

Poly(vinylidene fluoride) (PVDF) is a semi-crystalline polymer showing four crystalline forms, i.e. nonpolar $\alpha$-phase, and polar $\beta$-, $\gamma$-, and $\delta$-phases depending on the crystallization and processing conditions. It exhibits outstanding electroactive behavior, good chemical resistance and thermal stability [11, 12]. So it finds wide applications in the electronic, biomedical and membrane industries. With the recent progress in nanotechnology, a wide range of nanomaterials has been synthesized and produced for technological applications. So nanomaterials have been added to various polymers for improving their mechanical, physical and chemical properties [1319]. As mentioned before, hydrophobic PVDF membranes suffer from organic and biofouling greatly. Many efforts have been devoted to the development of PVDF-based nanocomposite membranes with antifouling property by adding metal and metal oxide nanomaterials. Iron with natural abundance of $91.754 \%$ is an ideal element for incorporating into polymer membranes for antifouling. However, environmental degradation of $\mathrm{Fe}[20,21]$ due to its extremely high chemical reactivity makes iron nanoparticles unsuitable for practical applications. In this respect, silver nanoparticles (AgNPs), $\mathrm{TiO}_{2}, \mathrm{SiO}_{2}$ nanoparticles, nanochitin whiskers, and grapheneoxide nanoplatelets have been added to PVDF to form nanocomposite membranes via the phase inversion method [22-24]. AgNPs are known to exhibit excellent antimicrobial resistance upon contact with bacterial cell membranes. In a recent study, LancerosMendez and coworkers prepared AgNP-PVDF nanocomposite films by solvent casting from a DMF solution [25]. They reported that particle size and concentration influence the crystallization of the electroactive $\gamma$-phase of PVDF. More recently, Zinadini reported that hydrophilic graphene oxide (GO) addition improves the fouling resistance of polyethersulfone by inhibiting the interaction between proteins and the membrane surface [26]. A similar finding was reported by Shukla et al. [27] for polyphenylsulfone membranes.

Electrospinning is a versatile process to produce polymer fibers with diameters ranging from several nanometers to micrometers under the application of an electric field. When the applied field overcomes the surface tension of polymer solution, a charged fluid stream is ejected from the tip of syringe onto a target collector [28-32]. Electrospun polymer membranes generally exhibit high porosity with interconnected open pores, and high surface area to volume ratio. In an earlier study, Gopal et al. [33] found that the liquid filtration performance of electrospun PVDF membranes is similar to that of conventional microfiltration membranes. Jang et al. [34] reported that electrospun PVDF-GO membranes exhibit three times higher water permeability than pure PVDF fibrous mats due to improved hydrophilicity. To enhance antimicrobial resistance of PVDF-GO fibrous mats, we need to incorporate AgNPs into this system. In this respect, electrospun PVDF-Ag-GO mats are expected to exhibit high water permeability and antifouling behavior. Little information is available in the literature regarding water permeability and antifouling property of electrospun PVDF-Ag-GO hybrid membranes. This study aims to develop new hybrid nanocomposite membranes and investigate the effects of GO-Ag hybrid filler additions on the tensile property, hydrophilicity, water permeability, protein and bacterial antifouling behavior of PVDFbased membranes prepared by electrospinning. Furthermore, the physical and tensile properties as well as antifouling performance of electrospun PVDF-Ag membranes are also studied for the purposes of comparison. The developed PVDF-based composites may also find a wide scope of application in the field of piezoelectric membranes for tissue engineering [12].

\section{Experimental procedure}

\subsection{Materials}

PVDF pellets (Kynar 740) used in this study were obtained from Arkema Inc. (U.S.A). Graphite flakes 
and bovine serum albumin (BSA) were bought from Sigma-Aldrich Inc. (St. Louis, MO, USA). Chemical reagents such as silver nitrate $\left(\mathrm{AgNO}_{3}\right)$, sulfuric acid $\left(\mathrm{H}_{2} \mathrm{SO}_{4}\right)$, hydrogen peroxide $\left(\mathrm{H}_{2} \mathrm{O}_{2}\right)$, potassium permanganate $\left(\mathrm{K}_{2} \mathrm{MnO}_{4}\right)$, sodium nitrate $\left(\mathrm{NaNO}_{3}\right), \mathrm{N}$, $\mathrm{N}$-dimethylformamide (DMF), acetone were of analytical grade and used as received. Lysogeny broth (LB), brain heart infusion (BHI) broth and bovine serum albumin (BSA) were purchased from Thermo Fisher Scientific Inc. (USA).

\subsection{Preparation of fibrous membranes}

\subsubsection{GO-Ag hybrids}

Graphene oxide was prepared according to a modified Hummers' method. In the process, graphite flakes and $\mathrm{NaNO}_{3}$ were placed in a volumetric flask containing concentrated $\mathrm{H}_{2} \mathrm{SO}_{4}$. The mixed solution was continuously stirred in an ice bath. Subsequently, $\mathrm{K}_{2} \mathrm{MnO}_{4}$ was slowly added to the solution, and the stirring was continuous for 2 days. The mixture was then diluted with slow addition of water. The reaction sequence was terminated by adding $\mathrm{H}_{2} \mathrm{O}_{2}$. The solution was finally centrifuged and the supernatant liquid decanted. The precipitate was treated with 3\% $\mathrm{HCl}$ and then washed with distilled water to remove the acid.

For making GO-Ag hybrids, GO was initially dispersed in DMF by bath sonication for $30 \mathrm{~min}$, then desired quantities of $\mathrm{AgNO}_{3}$ were introduced into the suspension. Sonication was used to exfoliate and break the as-prepared graphene oxide so that its lateral size falls mainly in tens to hundreds of nanometers. In the process, DMF served as both reducing agent and reaction medium. After sonication of further $30 \mathrm{~min}$, the suspension turned into a brown colloid solution. Subsequently, the reaction was magnetic stirred for $10 \mathrm{~h}$ at $60^{\circ} \mathrm{C}$. Pure AgNPs were synthesized by reduction of $\mathrm{AgNO}_{3}$ in $\mathrm{DMF}$ without $\mathrm{GO}$ addition.

\subsubsection{Electrospun polymer membranes}

To prepare pure PVDF membranes, PVDF pellets were dissolved in a mixture of acetone and DMF $(30: 70, \mathrm{v} / \mathrm{v})$, and stirred for $5 \mathrm{~h}$ at $50^{\circ} \mathrm{C}$. For the PVDF-Ag and PVDF-Ag-GO nanocomposite membranes, $20 \mathrm{wt} \%$ PVDF was first dissolved in acetone, followed by adding desired amounts of $\mathrm{Ag} / \mathrm{DMF}$ or GO-Ag/DMF suspensions under magnetic stirring for $5 \mathrm{~h}$. For the PVDF-Ag-GO system, GO content was fixed at $1 \mathrm{wt} \%$ while the AgNPs contents were kept at 1 and $2 \mathrm{wt} \%$ relative to the weight of PVDF. Electrospinning was performed using an electrospinning unit (NEU; Kato Tech Co., Japan) by loading the prepared solution into a syringe with a stainless steel needle tip having a diameter of $0.5 \mathrm{~mm}$. By applying a voltage of $20 \mathrm{kV}$, the solution was ejected from the needle tip at a rate of $0.05 \mathrm{~mL} / \mathrm{h}$. The distance between the needle tip and the collector was $12 \mathrm{~cm}$. A grounded, aluminum foil-wrapped rotating mandrel was used to collect fibrous membranes. The membranes were dried overnight in a vacuum dryer at $60^{\circ} \mathrm{C}$ to remove any residual solvents. The thickness of PVDF-based membranes was measured on five separate samples using a Mitutoyo digital micrometer as described elsewhere [35].

\subsection{Microscopic observations}

Graphene oxide and GO-AgNPs hybrids were first observed in an atomic force microscope (AFM; Veeco Nanoscope V). Scanning electron microscopy (SEM; Jeol JSM-820 and Jeol JSM 6700F) and transmission electron microscopy (TEM; Philips CM 20) images were taken to reveal the morphologies of PVDF-GO and PVDF-Ag-GO nanocomposite membranes. The diameters of electrospun PVDF-based fibers were determined from the SEM micrographs using Image J software (ImageJ, Bethesda, MD, USA). The porosity and pore size of electrospun membranes were also evaluated from the SEM images using ImageJ software. The SEM images were converted to grayscale where different layers were made distinct. By adjusting the pixel intensity to approximately select only the first layer of fibers and calculating this area fraction. From the literature, porosity results obtained from this image analysis were consistent with direct density measurements of the electrospun mats $[36,37]$.

\subsection{X-ray diffraction (XRD)}

The XRD patterns of fibrous membranes were obtained using a Bruker D2 Phaser X-ray diffractometer (Karlsruhe, Germany) equipped with $\mathrm{Cu}-\mathrm{K} \alpha$ radiation $(\lambda=0.154 \mathrm{~nm})$ at $30 \mathrm{kV}$. The patterns were recorded from 10 to $70^{\circ}$.

\subsection{Tensile measurements}

Tensile tests were performed for electrospun fibrous mats with a dimension of $50 \mathrm{~mm}$ (length), $10 \mathrm{~mm}$ (width) and a gauge length of $30 \mathrm{~mm}$ using an Instron 
tester (model 5567) at a crosshead speed of $10 \mathrm{~mm} / \mathrm{min}$. The stress-strain curves of fibrous membranes were recorded at room temperature. Five specimens of each composition were tested and the average value was reported.

\subsection{Silver ion release and contact angle tests} Electrospun nanocomposite membranes with AgNPs were sliced into circular disks having a diameter of $10 \mathrm{~mm}$. They were immersed in $10 \mathrm{~mL}$ deionized water for 1 to 28 days. The amount of silver ions released to the medium was quantitatively measured with inductively coupled plasma atomic emission spectrometry (ICP-AES; Perkin Elmer 3300DV).

Water contact angle measurements were carried out using deionized water drops as the probe liquid on the specimen surfaces. All experiments were conducted at room temperature with a Rame Hart 500-F1 advanced goniometer equipped with a camera (RameHart Instrument Co., NJ, USA). The measurements were repeated for six times on a given specimen and the average values were reported.

\subsection{Filtration performance measurements} 2.7.1 Water permeability and BSA rejection

The water permeability and BSA rejection of electrospun PVDF and its nanocomposite membranes was measured at room temperature with a dead-end filtration cell (Amicon stirred cell; model 8050) having a feed capacity of $50 \mathrm{~mL}$, and connected to a nitrogen gas line. The membranes exhibited an effective filtration area of $13.4 \mathrm{~cm}^{2}$. Each membrane was first flushed with deionized water at $0.1 \mathrm{MPa}$ for $30 \mathrm{~min}$ before testing. The water flux of a membrane was recorded at $0.1 \mathrm{MPa}$ as $J w_{1}$. The permeation flux was determined from the Equation (1) [23, 26]:

$$
J=\frac{V}{A \cdot \Delta t}
$$

where $V[\mathrm{~L}]$ is the deionized water or BSA solution permeate volume, $A\left[\mathrm{~m}^{2}\right]$ is the effective area of membrane, and $\Delta t[\mathrm{~h}]$ is the permeation time. Afterwards, aqueous BSA solution $(1.0 \mathrm{~g} / \mathrm{L})$ was applied to the membrane at a constant pressure of $0.1 \mathrm{MPa}$ for $30 \mathrm{~min}$, and recorded as $J_{\mathrm{p}}$. Once the BSA solution passed through the membrane, the permeate solution was collected. The BSA concentrations of the permeate and feed solutions were detected by an UVvis spectrophotometer (Lambda 2, Perkin Elmer) at a wavelength of $278 \mathrm{~nm}$. The BSA rejection $(R)$ was evaluated from Equation (2):

$R=\left(1-\frac{C_{p}}{C_{f}}\right) \cdot 100 \%$

where $C_{\mathrm{p}}$ and $C_{\mathrm{f}}$ are the BSA permeate concentration and the feed concentration, respectively. At least five replicates of water permeation and BSA fouling experiments were carried out in this study.

\subsubsection{Antifouling performance}

After BSA solution filtration, the membrane was washed by flushing with deionized water for $30 \mathrm{~min}$ and the water flux of clean membrane was measured again, denoting as $J w_{2}$. Accordingly, the flux recovery ratio $(F R R)$ was determined from the following expression given by Equation (3) $[23,26]$ :

$F R R=\frac{J w_{2}}{J w_{1}} \cdot 100 \%$

The fouling resistance performance can be further expressed by the following Equations 4) and (5):

$R_{r}=\frac{J w_{2}-J_{\mathrm{p}}}{J w_{1}} \cdot 100 \%$

$R_{i r}=\frac{J w_{1}-J w_{2}}{J w_{1}} \cdot 100 \%$

Herein reversible fouling ratio $\left(R_{\mathrm{r}}\right)$ refers to the flux decline due to the deposition of foulant on the membrane surface and cake layer formation, and irreversible fouling ratio $\left(R_{\mathrm{ir}}\right)$ describes the membrane fouling that cannot be removed by physical cleaning or chemical treatment. Five replicates of water cleaning experiments were performed accordingly.

\subsection{Antibacterial activity tests}

The bacterial strains used in this study were Gramnegative Escherichia coli (E. coli, ATCC 25922) and Gram-positive Staphylococcus aureus (S. aureus, ATCC 29213). E. coli and $S$. aureus were grown separately in fresh lysogeny broth (LB) and brain heart infusion (BHI) broth, and incubated overnight in an incubator shaker at $37^{\circ} \mathrm{C}$. Both bacterial suspensions were adjusted to McFarland method to achieve the desired bacterial concentration.

The antibacterial activities of fibrous membranes were determined by Bauer-Kirby disk diffusion method [38]. Bacterial suspension of $1 \cdot 10^{5} \mathrm{CFU} / \mathrm{mL}$ 
was evenly spread onto nutrient agar plates. Then sterilized disk specimens (6 $\mathrm{mm}$ diameter) were placed onto an agar surface, and the agar plates were incubated at $37^{\circ} \mathrm{C}$ for $18 \mathrm{~h}$. The inhibition zones were recorded with a digital camera. The diameter of inhibition zone was measured with a metric ruler having millimeter calibration. Six samples were tested for each type of membrane.

\section{Results and discussion}

\subsection{GO-Ag hybrid features}

As recognized, two dimensional graphene oxide (GO) sheet is produced by chemical oxidation of graphite in strong oxidizing solutions, which can be easily produced on a large scale. GO sheet is decorated with oxygen-containing functional groups such as hydroxyl,

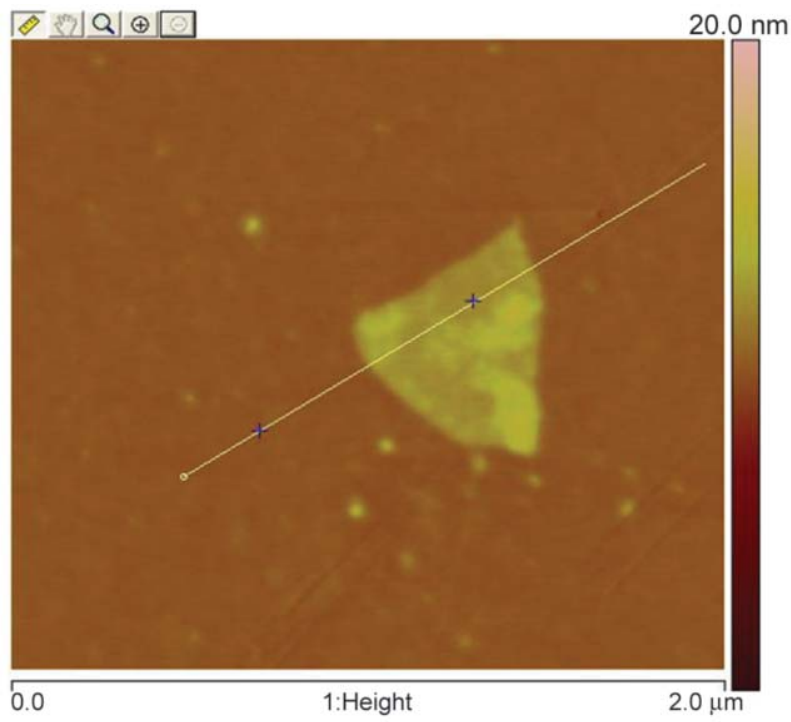

a)

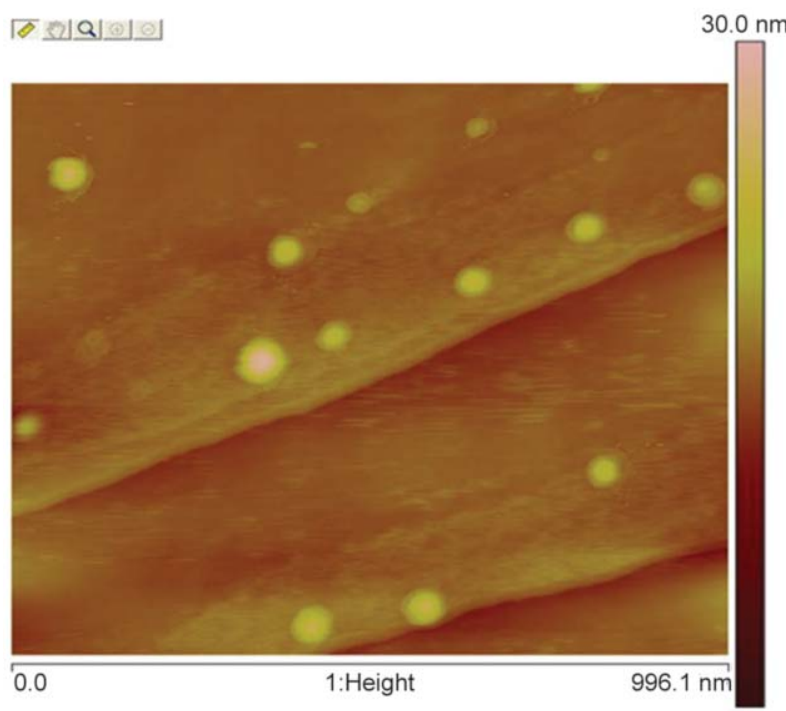

b) epoxy group, carbonyl and carboxyl groups. These functional groups render the GO sheet highly hydrophilic. Figure 1a is the AFM image of GO (with a lateral dimension of about $0.45 \mu \mathrm{m}$ ) deposited on a silicon substrate and its corresponding height profile. As shown in the AFM height profile, the thickness of GO sheet $(2-3 \mathrm{~nm})$ is somewhat larger than the thickness for pure graphene $(0.335 \mathrm{~nm})$ due to the presence of oxygenated groups in GO. Figures $1 \mathrm{~b}$ and $1 \mathrm{c}$ are the AFM and TEM images of GO-1\%Ag hybrid film. These figures reveal that the AgNPs are homogeneously dispersed throughout GO sheet. Apparently, GO sheet serves as effective sites for the nucleation and subsequent growth of AgNPs, thereby preventing AgNPs from aggregation [39-42]. The oxygenated groups of $\mathrm{GO}$ with surface negative charges
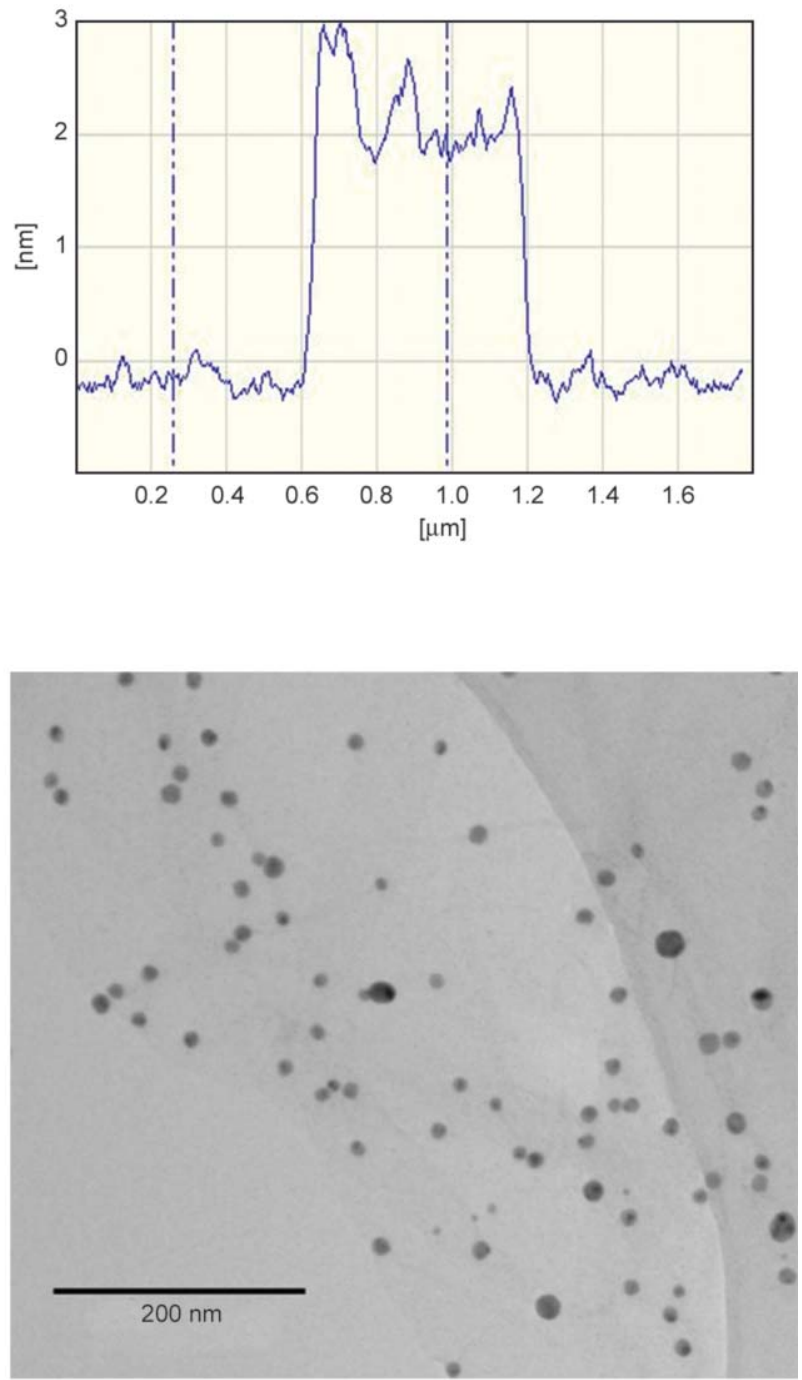

c)

Figure 1. AFM images of (a) GO and (b) GO-1\%Ag hybrid. (c) TEM micrograph of GO-1\%Ag hybrid 
provide active nucleation sites by attracting positive silver ions from silver nitrate. DMF solvent then reduces silver ions to AgNPs since DMF acting as both solvent and reducing agent [43, 44]. Consequently, most of the oxygenated functional groups of $\mathrm{GO}$ are removed, so insulating GO is converted to conducting reduced graphene oxide (rGO) $[45,46]$.

\subsection{Electrospun fibrous membranes}

Figures $2 \mathrm{a}-\mathrm{c}$ show representative SEM images of pristine PVDF, PVDF-1\% Ag and PVDF-1\% AgGO fibrous membranes. Figure $2 \mathrm{~d}$ is the TEM image showing uniform dispersion of AgNPs in the PVDF$1 \% \mathrm{Ag}$-GO fiber. The fiber diameters and porosity of all fibrous membranes as determined by image analysis from SEM micrographs are listed in Table 1. This table shows that the fibrous diameters of PVDF membranes decrease significantly by adding 1 and $2 \% \mathrm{Ag}$. The mean diameter of PVDF reduces from

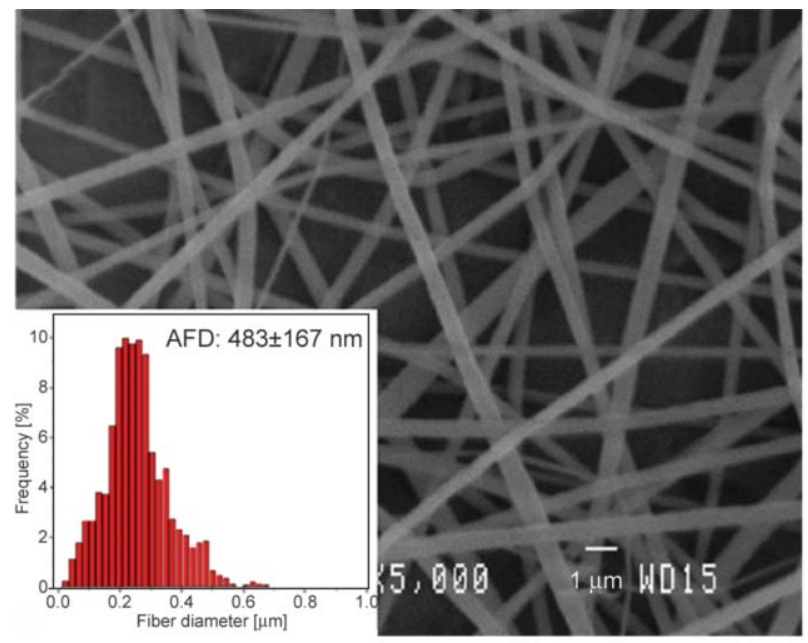

a)

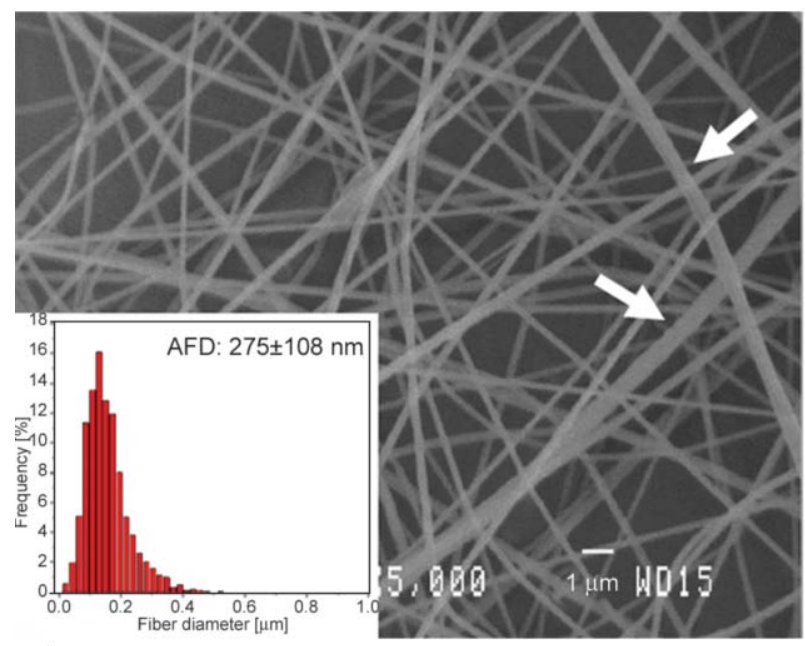

c)
$483 \pm 167$ to $290 \pm 121$ and $280 \pm 97 \mathrm{~nm}$, respectively. As mentioned before, sonication is employed to exfoliate and reduce the size of GO in nanometer scale so that GO can be included inside PVDF fiber. For the GOs with a lateral size of about $0.45 \mu \mathrm{m}$ (Figure 1a), the diameters of a few PVDF fibers will be increased to accommodate those GOs as indicated by the arrows in Figure 2c. The fiber size histograms

Table 1. Fiber diameter and porosity of electrospun membranes studied

\begin{tabular}{|l|c|c|}
\hline \multicolumn{1}{|c|}{ Sample } & $\begin{array}{c}\text { Fiber diameter } \\
\text { [nm] }\end{array}$ & $\begin{array}{c}\text { Porosity } \\
{[\text { [\%] }}\end{array}$ \\
\hline PVDF & $483 \pm 167$ & 49.3 \\
\hline PVDF-0.5\% Ag & $480 \pm 192$ & 49.4 \\
\hline PVDF-1\% Ag & $290 \pm 121$ & 55.3 \\
\hline PVDF-2\% Ag & $280 \pm 97$ & 56.7 \\
\hline PVDF-0.5\% Ag-GO & $333 \pm 137$ & 52.6 \\
\hline PVDF-1\% Ag-GO & $275 \pm 108$ & 56.9 \\
\hline PVDF-2\% Ag-GO & $265 \pm 92$ & 58.2 \\
\hline
\end{tabular}

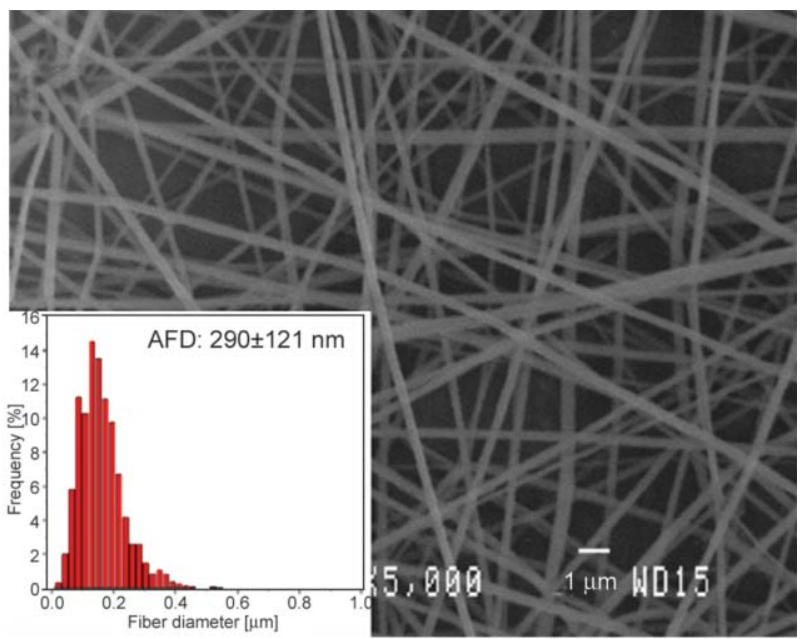

b)

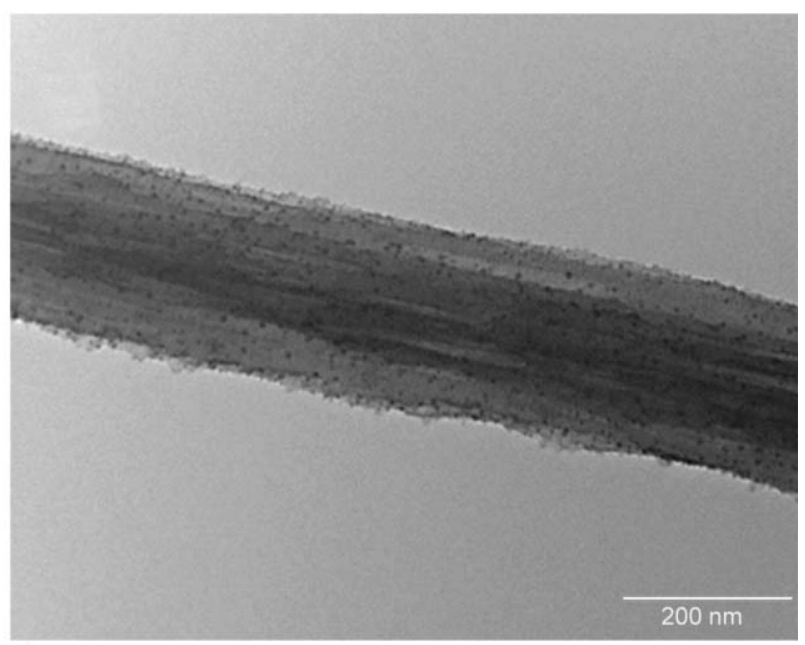

d)

Figure 2. SEM images of (a) PVDF, (b) PVDF-1\%Ag and (c) PVDF-1\% Ag-GO fibrous membranes. (d) TEM image of electrospun PVDF-1\% Ag-GO fiber 
also reveal that a few fibers have a larger diameter of about $0.48 \mu \mathrm{m}$.

From Table 1, the membrane porosity decreases with increasing fiber diameter. Electrospun fibrous membranes generally have the porosities in the range of about $30-89 \%$, depending on the processing parameters [25, 28, 30, 34, 47]. For example, Hwang et al. [48] reported that the porosity of electrospun PVDF mats falls in the range of $35-48 \%$, while Coreia et al. [49] reported a porosity of $79 \%$. The factors affect electrospinning include polymer solution parameters, i.e. the selection of polymers with suitable solvents, solution concentration, solution conductivity, and the processing conditions such as applied voltage, flow rate, needle diameter, distance from the needle to the collector, etc. [25, 30]. In general, the processing conditions have certain influence on fiber morphology although they are less significant than the solution parameters. In this study, DMF/acetone mixed solvent can facilitate the fiber formation without beads. By electrospinning PVDF/DMF solution, fiber generation becomes difficult due to the high boiling temperature $\left(153^{\circ} \mathrm{C}\right)$ and low evaporation rate of DMF solvent. To increase the evaporation rate of solvent, acetone with low boiling temperature of $56.8^{\circ} \mathrm{C}$ and higher volatility is employed as a co-solvent [50]. In addition, polymer solutions with $20 \mathrm{wt} \%$ PVDF can produce fibrous membranes due to their adequate viscosity. Below this polymer concentration, beads are formed owing to low viscosity of the solution. As such, the entanglement of the molecules is not strong enough to overcome the repulsion of positive charge arising from the applied external voltage a [30]. Formation of beads is common in polymer solutions with lower concentrations. On the other hand, filler additions tend to increase the viscosity of electrospun polymer solutions [51, 52]. Thus adding nanofillers can increase the fiber diameter by increasing the solution viscosity. However, if nanofillers are conducting materials such as AgNPs and $\mathrm{rGO}$, they can strengthen the repulsive force and decrease the fiber diameter by increasing the solution conductivity. Thus there is a balance between increased viscosity and increased repulsive force in forming fibrous membranes during electrospinning. Typically, the conductivity of polymer solutions can be increased by adding conducting additive such as $\mathrm{NaCl}$. The addition of a few salt molecules leads to a higher charge density on the surface of the ejected jet, generating stronger repulsive forces $[53,54]$. In this study, conducting AgNPs and rGO exhibit good electrical conductivity, thus their additions to PVDF increase the conductivity of polymer solutions [55], giving rise to nanocomposite fibrous membranes with finer diameters than pristine PVDF mat. Increasing polymeric solution conductivity generally results in the formation of finer fibers because the ejecting jet stream can carry more electric charges. As the charge carried by the jet increases, a greater stretching and elongation of the jet takes place during electrospinning, thereby producing fine fibers [51-53]. Table 1 also indicates that the incorporation of $1 \% \mathrm{GO}$ into PVDF- $0.5 \%$ Ag, PVDF-1\% Ag and PVDF-2\% Ag membrane refines their fibrous diameters markedly. As mentioned before, functional groups of GO such as carboxylic acid, hydroxyl, or epoxide groups interact with silver ions to form AgNPs in the GOAgNP hybrid. This leads to the reduction and conversion of insulating GO to conducting reduced graphene oxide (rGO) $[45,46]$. In this regard, rGO fillers also increase the conductivity of polymer solution.

The dispersion of GO and AgNP nanofillers in the PVDF matrix is now considered. Graphene oxide interacts strongly with polar polymers. In polar PVDF, fluorine is more electronegative than carbon, the fluorine atoms will pull electrons away from the carbon atoms to which they are attached. This implies that the $-\mathrm{CF}_{2}-$ groups in the PVDF chain is very polar. Recently, El Achaby et al. [56] prepared GO/PVDF nanocomposites and reported that GOs were homogeneously dispersed within the PVDF matrix due to the strong and specific interaction between carbonyl group (CO) of $\mathrm{GO}$ and fluorine group $\left(-\mathrm{CF}_{2}-\right)$ in PVDF. Furthermore, Manna et al. [57] reported that an electrostatic interaction between the charges on AgNPs and the $\mathrm{CF}_{2}$ dipole of PVDF straightens the $\mathrm{PVF}_{2}$ chains, leading to the formation of $\beta$-phase conformation. Therefore, specific interactions between GO and AgNPs with the PVDF molecular chains would result in good interfacial bonding with PVDF, leading to their uniform dispersion in the matrix.

Figure 3 shows representative field emission-SEM image of electrospun PVDF membrane. Very fine nanopores can be readily seen on the surface of some fibers at a high magnification. The surface pores on the fibers are induced by the phase separation due to the fast solvent evaporation and air vapor penetration $[58,59]$. The pore formation mechanism is rather complicated. During electrospinning in an air atmosphere, a cylindrical polymer fluid jet initially consists of 


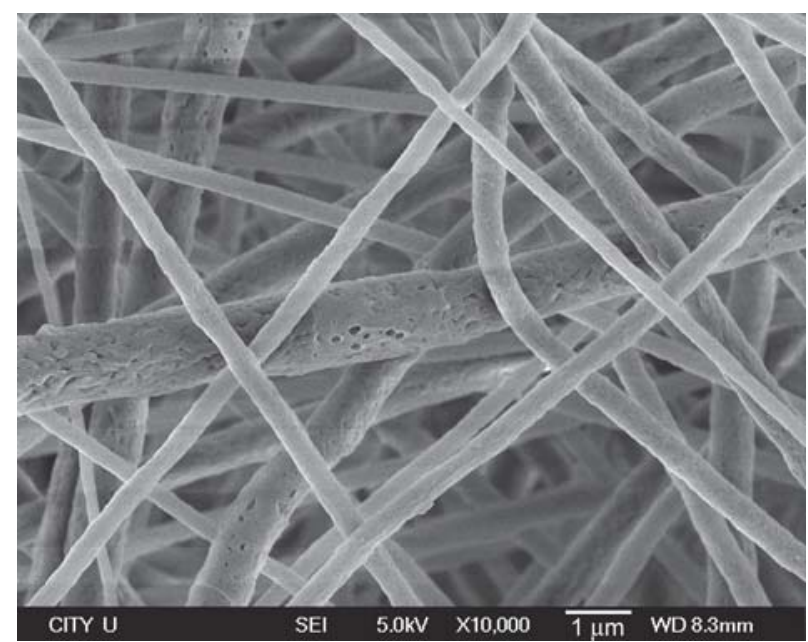

Figure 3. Field emission-SEM image of electrospun PVDF membrane showing nanopores on the fibers

polymer chains and solvent molecules. At this stage, simultaneous diffusion processes of solvent evaporation outward and air vapor penetration inward take place at the polymer-air interface. By evaporating solvent, concentrated polymer rich-phase solidifies into the matrix, whereas the solvent-rich phase transforms into pores as the solvent evaporates [58]. The nanopores on the fibers play an important role in wetting AgNPs embedded inside hydrophobic PVDF fibers to generate silver ions as discussed later.

$\mathrm{X}$-ray diffraction is a useful technique for verifying the structures and phases developed in the nanocmposite membranes as a result of electrospinnng and $\mathrm{Ag}$-GO nanofiller additions. Figure 4 shows the XRD pattern of electrospun PVDF, PVDF-1\% Ag-GO and PVDF-2\% GO membranes. This pattern reveal typical Ag peaks at $38.1,44.2,64.4^{\circ}$, corresponding to

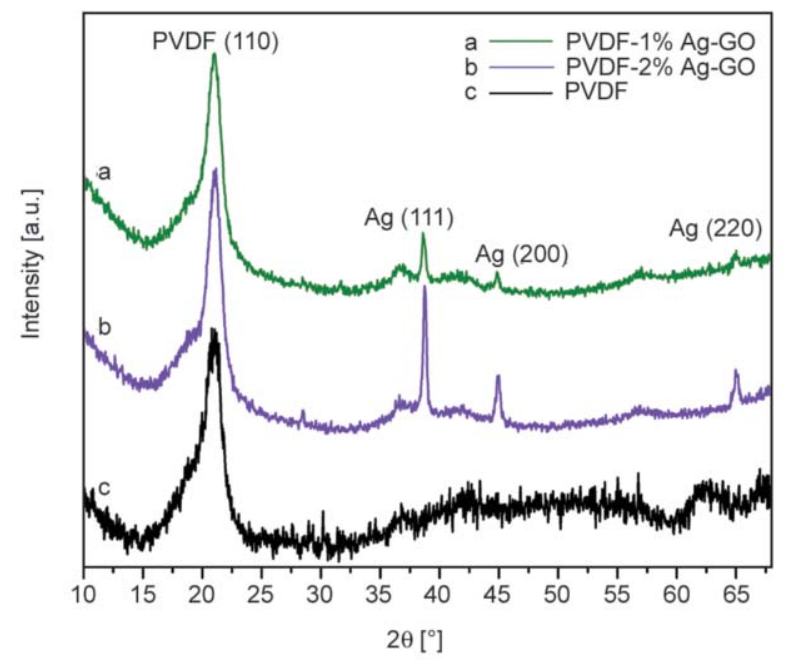

Figure 4. X-ray diffraction patterns of electrospun PVDF, PVDF-1\% Ag-GO and PVDF-2\% Ag-GO fibrous membranes the (111), (200) and (220) reflections, implying the presence of AgNPs in the PVDF matrix of composite membranes. Moreover, PVDF, PVDF-1\% Ag-GO and PVDF-2\% Ag-GO samples show a strong reflection at $2 \theta=20.6^{\circ}$, corresponding to the (110) reflection of $\beta$-phase PVDF. From the literature, PVDF exhibits four crystalline forms, i.e. nonpolar $\alpha$-phase, and polar $\beta-, \gamma$-, and $\delta$-phases depending on the crystallization and processing conditions [11]. The $\alpha-$ phase crystallizes from the melt directly, while the $\beta$-phase generates from mechanical stretching and solvent casting $[14,60]$. In the present study, electrospinnig can also induce $\triangle$-phase in pristine PVDF mat. This can be attributed to the polymer molecules of fluid jet stream experience stretching motion during electrospinning. This causes a significant elongation of the electrospun jet under a high stretching rate. In this respect, entangled polymer chains in the jet undergo molecular reorganization. The induction of $\beta$ phase in pristine PVDF prepared by electrospinning has been reported by Sundaray et al. [61]. In general, nanomaterials can also induce the formation of $\beta$ phase PVDF. In particular, AgNPs, GO or rGO addition promotes the formation of $\beta$-phase PVDF [57, 62, 63]. Manna et al. [57] reported that an electrostatic interaction between the charges on AgNPs and the $\mathrm{CF}_{2}$ dipole of $\mathrm{PVDF}$ straightens the $\mathrm{PVF}_{2}$ chains, leading to the formation of $\beta$-phase conformation. As such, the XRD patterns of PVDF-1\% Ag-GO and PVDF-2\% Ag-GO samples show distinct $\beta$-phase reflection at $2 \theta=20.6^{\circ}$. From Figure 4 , the absence of characteristic GO peak in the XRD patterns of PVDF-1\% Ag-GO and PVDF-2\% Ag-GO membranes implies that the GO is exfoliated in the PVDF matrix and reduced to $\mathrm{rGO}[64,65]$.

\subsection{Mechanical behavior}

Figure 5 shows the tensile stress-strain curves of PVDF and its nanocomposite membranes. Apparently, all composite membranes exhibit higher elastic modulus, tensile strength and tensile ductility than pristine PVDF mat. Bulk PVDF exhibits a tensile strength of 35-50 MPa. In this study, the presence of porosity in PVDF membrane reduces its tensile strength to $3.7 \pm 0.4 \mathrm{MPa}$. Our tensile strength for porous PVDF membrane agrees reasonably with that reported in the literature with a tensile strength of $4 \mathrm{MPa}$ [66]. A small variation in strength is due to different processing conditions in forming fibers. The elastic modulus and tensile strength of PVDF 


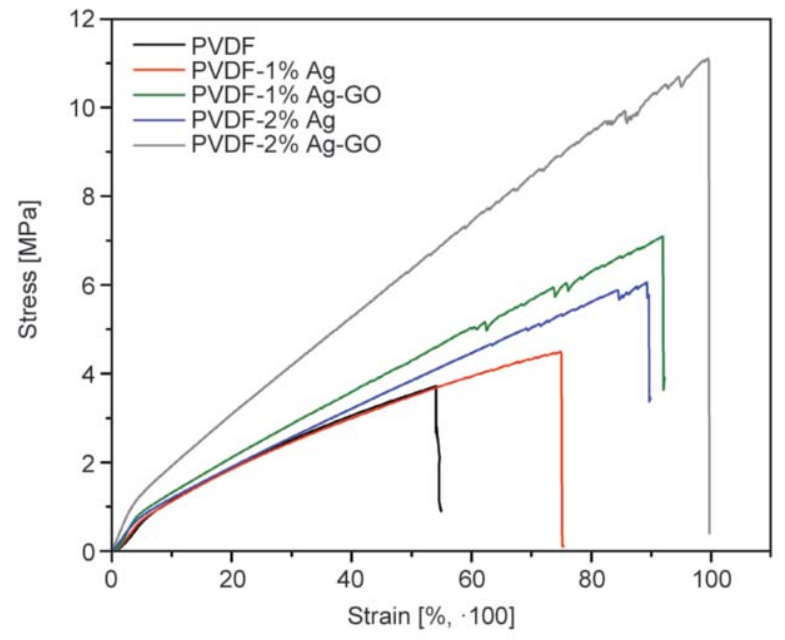

Figure 5. Tensile stress-strain curves of electrospun PVDF and its nanocomposite membranes

increase considerably by adding AgNPs. At a filler loading of $2 \% \mathrm{Ag}$, the tensile strength of nanocomposite reaches $5.8 \pm 0.1 \mathrm{MPa}$, corresponding to an improvement of $55.38 \%$ over that of pure PVDF mat. This demonstrates that AgNPs can bear the tensile load effectively. The load-bearing capacity arises from an efficient stress-transfer across the filler-matrix interface of this nanocomposite, resulting from an electrostatic interaction between the charges on AgNPs and the $\mathrm{CF}_{2}$ dipole of PVDF as mentioned above [57]. The elastic modulus, tensile strength and elongation at break of electrospun fibrous membranes are listed in Table 2 .

Graphene exhibits extraordinarily high elastic modulus of $1 \mathrm{TPa}$ and tensile strength of $130 \mathrm{GPa}$ [67]. However, GO exhibits a tensile strength of $87.9 \mathrm{MPa}$ and lower elastic modulus in the range of 270 $470 \mathrm{GPa}$ due to the variations in coverage of oxygen groups $[68,69]$. The elastic modulus and tensile strength of GO are considerably higher than those of pristine PVDF. The GO additions can improve mechanical strength and stiffness of the polymer composites [70]. By adding $1 \% \mathrm{GO}$ to PVDF- $1 \% \mathrm{Ag}$, the tensile strength, elastic modulus and elongation further

Table 2. Tensile properties of electrospun PVDF and its nanocomposites studied

\begin{tabular}{|l|c|c|}
\hline \multicolumn{1}{|c|}{ Sample } & $\begin{array}{c}\text { Young's modulus } \\
\text { [MPa] }\end{array}$ & $\begin{array}{c}\text { Tensile strength } \\
\text { [MPa] }\end{array}$ \\
\hline PVDF & $168.9 \pm 9.5$ & $3.7 \pm 0,4$ \\
\hline PVDF-1\% Ag & $177.3 \pm 11.2$ & $4.5 \pm 0.5$ \\
\hline PVDF-2\% Ag & $184.3 \pm 8.1$ & $5.8 \pm 0.1$ \\
\hline PVDF-1\% Ag-GO & $258.9 \pm 5.4$ & $7.1 \pm 0.6$ \\
\hline PVDF-2\% Ag-GO & $321.6 \pm 8.5$ & $11.1 \pm 0.1$ \\
\hline
\end{tabular}

increase markedly. This is due to uniform dispersion of AgNPs in the PVDF matrix since GO acting as an effective layer for anchoring AgNPs. Furthermore, the interaction between carbonyl group of GO and fluorine group $\left(\mathrm{CF}_{2}\right)$ in PVDF also contributes to an increase in tensile strength elastic modulus and tensile elongation of the PVDF-GO nanocomposites [56]. Enhanced tensile strength, elastic modulus and tensile elongation is also observed by adding $1 \% \mathrm{GO}$ to PVDF-2\% Ag. As such, the incorporation of AgNP and GO nanofillers into PVDF render the resulting nanocomposite membranes can withstand applied stress during water filtration, and prevent the collapse of the porous structure of membranes. From these results, it is apparent that the specific interactions between GO and AgNPs with the PVDF matrix are responsible for enhanced tensile elongation of the PVDF-based nanocomposite membranes. Furthermore, induced $\beta$-phase due to the GO and AgNP nanofillers is also beneficial in enhancing tensile elongation of PVDF. Giannellies and coworkers reported that the tensile elongation of PVDF-clay nanocomposites is significantly higher than that of pristine PVDF owing to the filler-induced $\beta$-phase formation [71].

\subsection{Enhanced membrane wetting}

For practical applications in industries, it is beneficial to develop membranes with improved hydrophilicity to prevent fouling by organic contaminants and bacterial species. The water contact angle measurement is a useful technique for assessing wettability of the fibrous membranes. Figure 6 is a photograph showing the shapes of water droplets on all electrospun membrane surfaces. Pristine PVDF fibrous membrane displays a high contact angle of $141.9 \pm 0.8^{\circ}$, implying its hydrophobic behavior. Adding $0.5 \%$ Ag to PVDF slightly decreases its contact angle with water to $139.1 \pm 0.4^{\circ}$. As the $\mathrm{Ag}$ content of PVDF increases to 1 and $2 \% \mathrm{Ag}$, water contact angle decreases to $133.4 \pm 1.3$ and $124.3 \pm 0.9^{\circ}$, respectively. Apparently, a decrease in contact angle with the incorporation of AgNPs into the PVDF matrix demonstrates a reduction in the degree of hydrophobicity of materials. By hybridizing $\mathrm{GO}$ with $\mathrm{Ag}$ in the PVDF-1\% Ag and PVDF-2\% Ag nanocomposites, water contact angle is further reduced to $127.3 \pm 0.5$ and $121.1 \pm 1.1^{\circ}$. The PVDF-2\% Ag-GO nanocompsite fibrous membrane is found to exhibit the lowest water contact angle. As mentioned before, insulating $\mathrm{GO}$ is converted to conducting $\mathrm{rGO}$ 


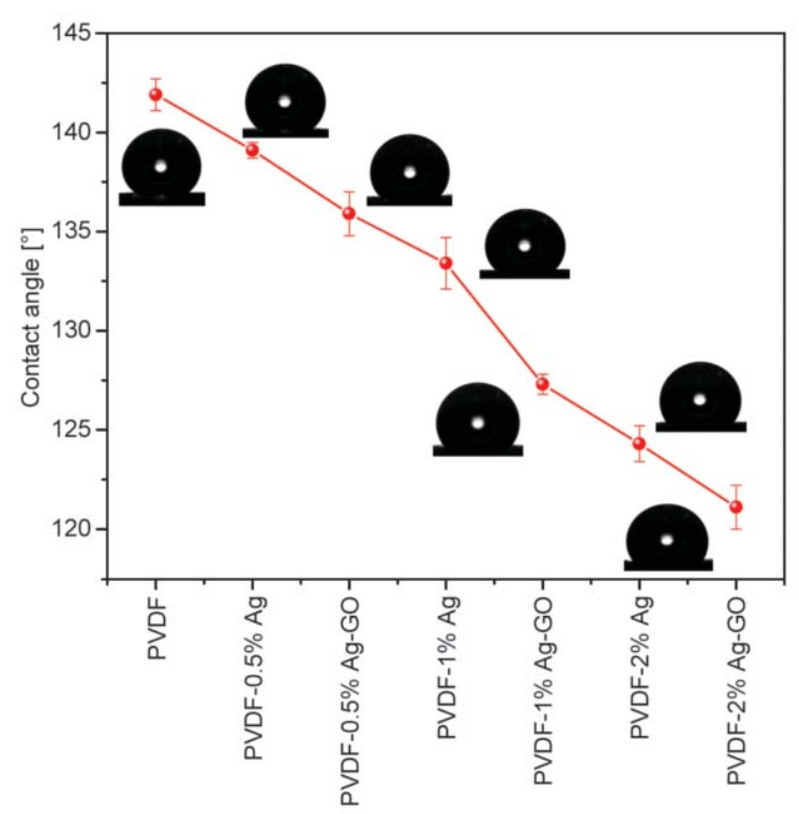

Figure 6. Photograph of water droplets on electrospun PVDF and its nanocomposite membrane surfaces

during sample preparation; rGO contains fewer oxygenated groups than GO, i.e. GO is more hydrophilic than rGO. In this respect, Ag content dominates the reduction of contact angle rather than rGO. It is noted that the contact angle obtained in electrospun polymer mat is much higher than that of its corresponding membrane prepared by the phase-inversion. For example, the contact angle of electrospun PVDF mat in this study is $141.9 \pm 0.8^{\circ}$. However, water contact angle of phase-inverted PVDF mat is only $99.2^{\circ}$ [23]. The increase of contact angle in electrospun polymer membrane is related to the complication of interacting factors on the mat surface such as fiber diameter, porosity and surface roughness [72].

Metal nanoparticles have been added generally to polymers for enhancing their hydrophilicity. For Agcontaining membranes, a decrease of contact angle results from the presence of AgNPs and their subsequent conversion to $\mathrm{Ag}^{+}$ions upon contacting with aqueous environment. The incorporation of GO into PVDF matrix reduces the hydrophobicity due to the presence of oxygenated groups. Thus Ag-containing nanocomposites with lower contact angles favor the release of the silver ions upon immersion in water environment. The degree of hydrophobicity reduction depends largely on the Ag content and the presence of GO in the composites. Figure 7 shows the $\mathrm{Ag}^{+}$ concentration released by electrospun PVDF-Ag and PVDF-Ag-GO nanocomposite systems immersed in deionized water for 28 days. Apparently, PVDF$0.5 \% \mathrm{Ag}$, PVDF- $0.5 \% \mathrm{Ag}-\mathrm{GO}$ and PVDF- $1 \% \mathrm{Ag}$

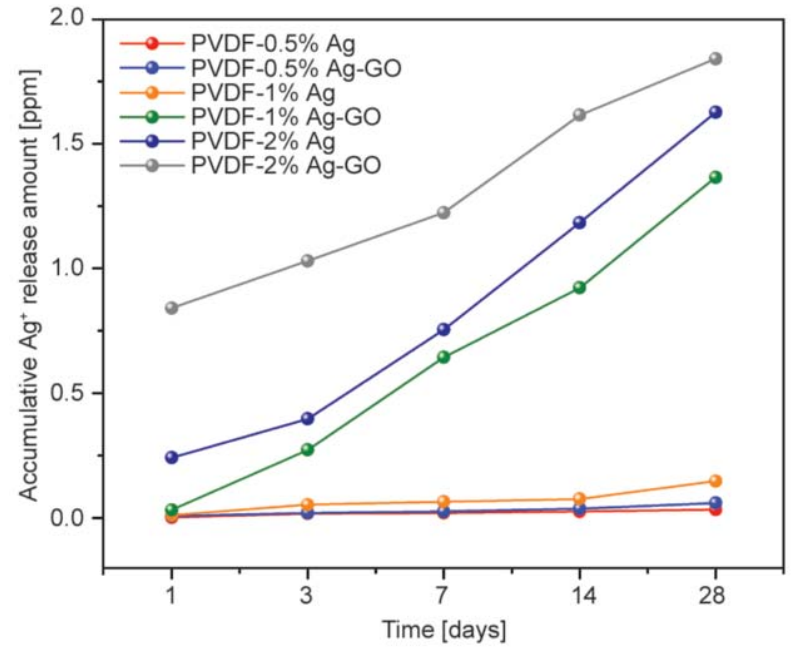

Figure 7. Silver ion released from the PVDF-Ag and PVDFAg-GO nanocomposite systems immersed in deionized water for 28 days

fibrous membranes release very small amounts of silver ions in deionized water for 28 days. However, a substantial amount of $\mathrm{Ag}^{+}$ions is released by incorporating GO into PVDF-1\% Ag membrane. Moreover, the concentration of released $\mathrm{Ag}^{+}$ions of this membrane rises greatly with the time periods of prolonged immersion. By increasing Ag loading level in the PVDF-Ag system to $2 \%$, larger amounts of $\mathrm{Ag}^{+}$ ions are released from the fibrous membrane. So AgNPs of PVDF-2\% Ag can be oxidized electrochemically to $\mathrm{Ag}^{+}$ions by immersing in deionized water. Furthermore, PVDF-2\% Ag-GO membrane releases the highest $\mathrm{Ag}^{+}$ion concentrations as expected.

\subsubsection{Water permeability and antifouling behavior}

Figure 8 shows the water flux permeability and BSA rejection values of PVDF and its nanocomposite membranes. Apparently, pristine PVDF exhibits the lowest water flux due to its hydrophobicity. The water permeability of PVDF is greatly improved by adding $1 \% \mathrm{Ag}$ and $2 \% \mathrm{Ag}$. Further enhancement in water permeability can be achieved through the addition of $1 \% \mathrm{GO}$ to PVDF-1\% Ag and PVDF-2\% Ag membranes. This can be attributed to the decrease of PVDF hydrophobicity by adding $\mathrm{Ag}$ or $\mathrm{Ag} / \mathrm{GO}$ nanofillers. The oxygenated functional groups of GO can attract water molecules effectively. Thus the oxygenated groups of $\mathrm{GO}$ and $\mathrm{Ag}^{+}$ions (from AgNPs) favor the attraction of water molecules inside the membrane matrix and facilitates water to filtrate through the membrane, thus enhancing the permeability. Very 


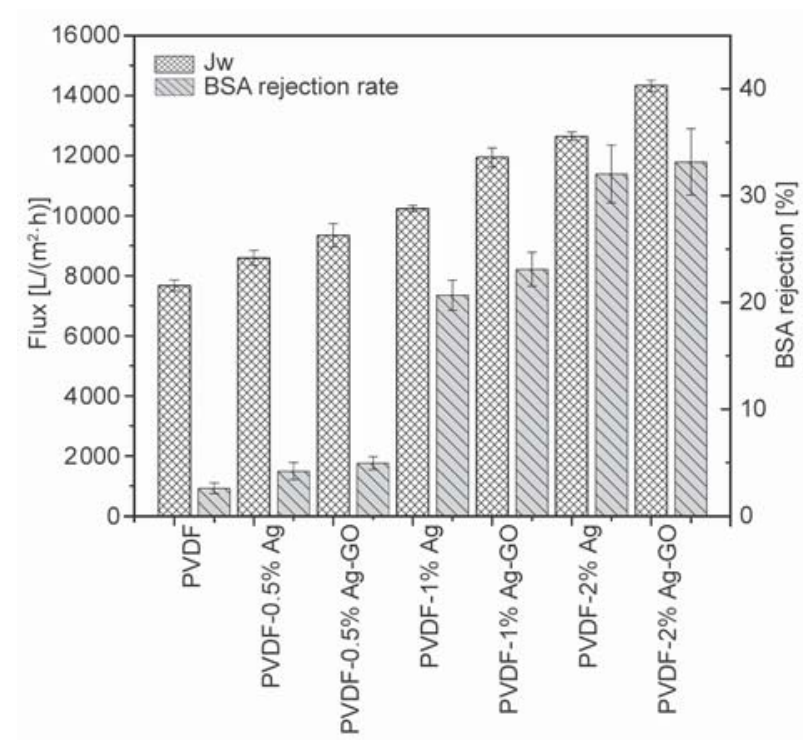

Figure 8. Water permeability and BSA rejection of electrospun PVDF and its nanocomposite membranes

recently, Wang et al. [73] reported that the water flux of electrospun polyacrylonitrile membranes increases with increasing porosity and fiber diameter. From Table 1 and Figure 8, it is evident that the water flux of membranes increases with the increase of porosity. This is because higher porosity in the membranes provides more water flow channels. In general, the fiber diameter of electrospun membranes has a direct relationship with the pore size. By decreasing the diameter of electrospun membranes, small pores are produced accordingly $[73,74]$. As recognized, fined pores in electrospun membranes are formed through layer-by-layer stacking of fibers to create an interconnected structure. On the basis of image analysis using ImageJ, the pore sizes of pure PVDF, PVDF$2 \% \mathrm{Ag}$ and PVDF- $2 \% \mathrm{Ag}$-GO membranes are determined to be $1.49,0.69$ and $0.63 \mu \mathrm{m}$, respectively. Although PVDF has larger pores than the composite membranes, its highly hydrophobic nature and low porosity lead to lowest water flux permeability. In contrast, polymer membranes with more porous features have smaller-sized pores [75]. PVDF-based composite membranes especially PVDF-2\% Ag and PVDF-2\% Ag-GO with highest porosity and lowest water contact angle counterbalance the effect of smaller pores, leading to enhanced water flux permeability.

In this study, BSA is employed as a model protein to assess the fouling resistance of the membrane. Figure 8 reveals that the incorporation of $\mathrm{Ag}$ or $\mathrm{Ag} /$ GO nanofillers into PVDF membranes enhances their BSA rejection rate significantly. Hydrophobic PVDF favors the adhesion of hydrophobic BSA on its surface as expected. By reducing the degree of hydrophobicity of PVDF through GO and AgNP additions, the adsorption of BSA is inhibited; such effect depends on the filler concentrations. Accordingly, PVDF$2 \% \mathrm{Ag}$ and PVDF-2\% Ag-GO membranes show the highest $\mathrm{BSA}$ rejection rate. Although the addition of $1 \% \mathrm{Ag}$ to PVDF reduces the degree of hydrophobicity to a certain extent, it is unclear how it would increase the BSA rate dramatically. More work is needed to elucidate this issue.

The protein antifouling performance of electrospun PVDF-Ag and PVDF-GO-Ag membranes can be evaluated by measuring the water flux recovery after fouling with a BSA solution. From Figure 9, the FRR value of pristine PVDF membrane is $70.8 \pm 3.2 \%$ due to the deposition and pore blocking by BSA protein. However, the flux recovery percentage of PVDF-Ag and PVDF-GO-Ag membrane systems are substantially improved comparing with pure PVDF membrane. The FRR value of PVDF-Ag membranes increases with increasing Ag content. Hybridization Ag with GO further enhancing FRR values of the PVDF-GO-Ag membranes, particularly for the PVDF-2\% Ag-GO with a relatively high value of $93.8 \pm 2.6 \%$. Such a high FRR value demonstrates a better antifouling property for the membrane.

In general, membrane fouling can be classified into reversible and irreversible fouling. For reversible fouling, the fouling agents are loosely adhered to the membrane, and can be removed by simple hydraulic cleaning and backwashing. Irreversible fouling is

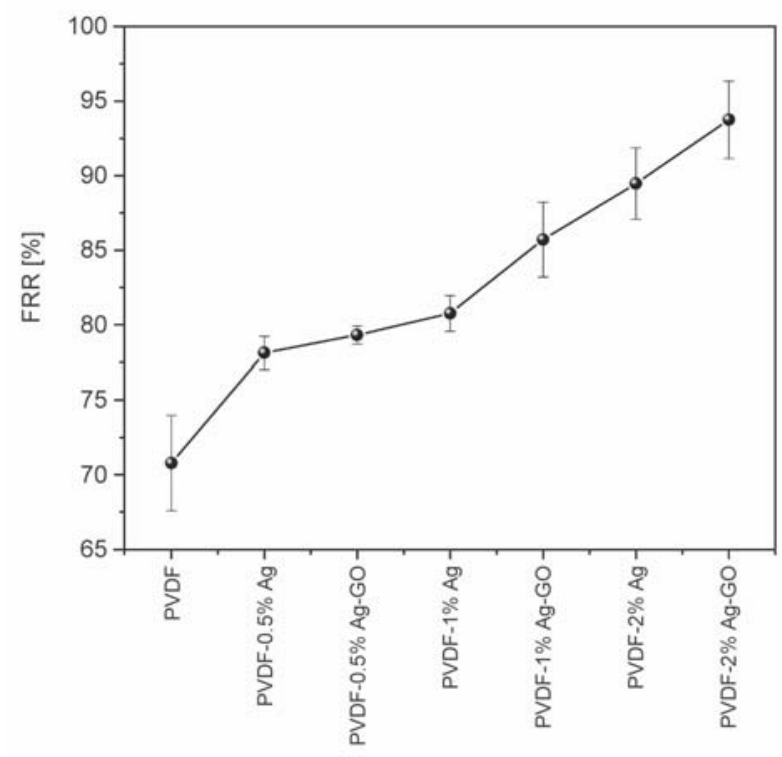

Figure 9. FRR values of electrospun PVDF and its nanocomposite membranes 
caused by the strong adsorption of protein molecules on the membrane surface and entrapment of foulant molecules in the pores. Figure 10 shows the fouling resistance ratios of PVDF and its nanocomposite membranes. Electrospun PVDF membrane exhibits a $R_{\text {ir }}$ value of $30 \%$ and $R_{\mathrm{r}}$ of $3 \%$ because of serious membrane fouling. So irreversible fouling dominates over $R_{\mathrm{r}}$ in the PVDF mat due to the hydrophobic interactions between the membrane surface and foulant. By adding 0.5, 1 and 2\% Ag to PVDF, irreversible fouling percentage reduces to 22,19 and $11 \%$, while reversible fouling ratio increases to $9 \% .19$ and $36 \%$, respectively. Larger $R_{\mathrm{r}}$ implies that the adsorbed foulants can be removed from the membrane surface by washing with water. A marked reduction in the $R_{\text {ir }}$ values implies that the antifouling capability of nanocomposite membranes improves dramatically due to a reduction in hydrophobicity of these membranes. This inhibits the deposition of BSA protein during filtration, thereby preventing the blocking of membrane pores. These results are of practical importance since the adsorbed protein layer on membrane pores can also act as a site for bacterial adhesion and subsequent colonization, leading to the formation of biofilm. For the PVDF-2\% Ag-GO membrane, $R_{\text {ir }}$ value further drops to $6 \%$ while $R_{\mathrm{r}}$ increases to $47 \%$. Thus electrospun PVDF-2\% Ag-GO membrane with high $F R R$ and low $R_{\text {ir }}$ renders it with excellent antifouling performance.

As recognized, particulate foulants on the membranes can block the pores which increases the re-

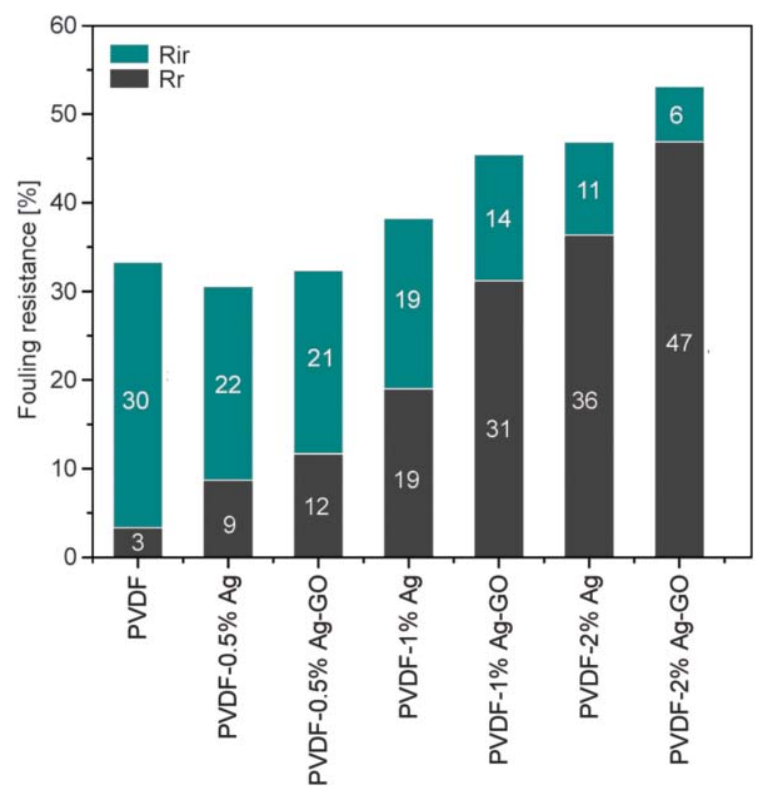

Figure 10. Fouling resistance of electrospun PVDF and its nanocomposite membranes sistance to water flow, resulting in a decline in water flux permeability. Gopal et al. [33] fabricated electrospun PVDF membranes with pore sizes in the range of 4-10.6 $\mu \mathrm{m}$, and the membranes were used to separate 1,5 and $10 \mu \mathrm{m}$ polystyrene particles. They reported that the membranes can remove micro-particles in the range of 5-10 $\mu \mathrm{m}$ effectively during filtration. Generally, pore blocking mechanism tends to increase with increasing membrane pore size [76]. It is easier for fine particles (smaller than the membrane pore size) to enter the membrane pores and get trapped in them, resulting in pore blocking. With smaller pores, large particles rapidly form a top layer on the membrane and collect the smaller particles. Large particles can then be removed easily by a simple hydraulic cleaning [76]. In this respect, pristine PVDF membrane with a larger diameter and pore size of $1.49 \mu \mathrm{m}$ is expected to experience more pore blocking than the PVDF-2\% Ag and PVDF-2\% Ag-GO composite membranes with smaller diameters and respective pore sizes of 0.69 and $0.63 \mu \mathrm{m}$.

\subsection{Antibacterial activity}

As mentioned before, biofilm formation arises from the early adhesion of bacteria, their subsequent proliferation and colonialization on the membrane surface. The biofilm formation on the membranes is affected by the presence of bacterial species with different cell walls and structures of the EPS produced [77]. Gram-negative E. coli is widely present throughout aquatic environments and used as the model organism for biofilm formation on the membranes [78]. It is generally known that all PVDF phases have no antibacterial activity; their antifouling behavior depends on the addition of antibacterial nanofillers such as silver [22]. In general, bacteria adhere to hydrophobic polymer membranes through hydrophobic-hydrophobic interactions between their cell walls and the membrane surface. Thus hydrophobic PVDF membrane favors the bacteria to adhere to its surface. However, PVDF-Ag and PVDF-GO-Ag membranes can inhibit bacteria from attaching to the membrane surfaces by releasing $\mathrm{Ag}^{+}$ions. Very recently, Monerris et al. [79] reported that hydrogel nanocomposites loaded with AgNPs show antibacterial activity by releasing $\mathrm{Ag}^{+}$ions from $\mathrm{AgNPs}$ reside in the matrix.

Figure 11a shows the agar plate cultured with Gramnegative $E$. coli and then contacted directly with pure 

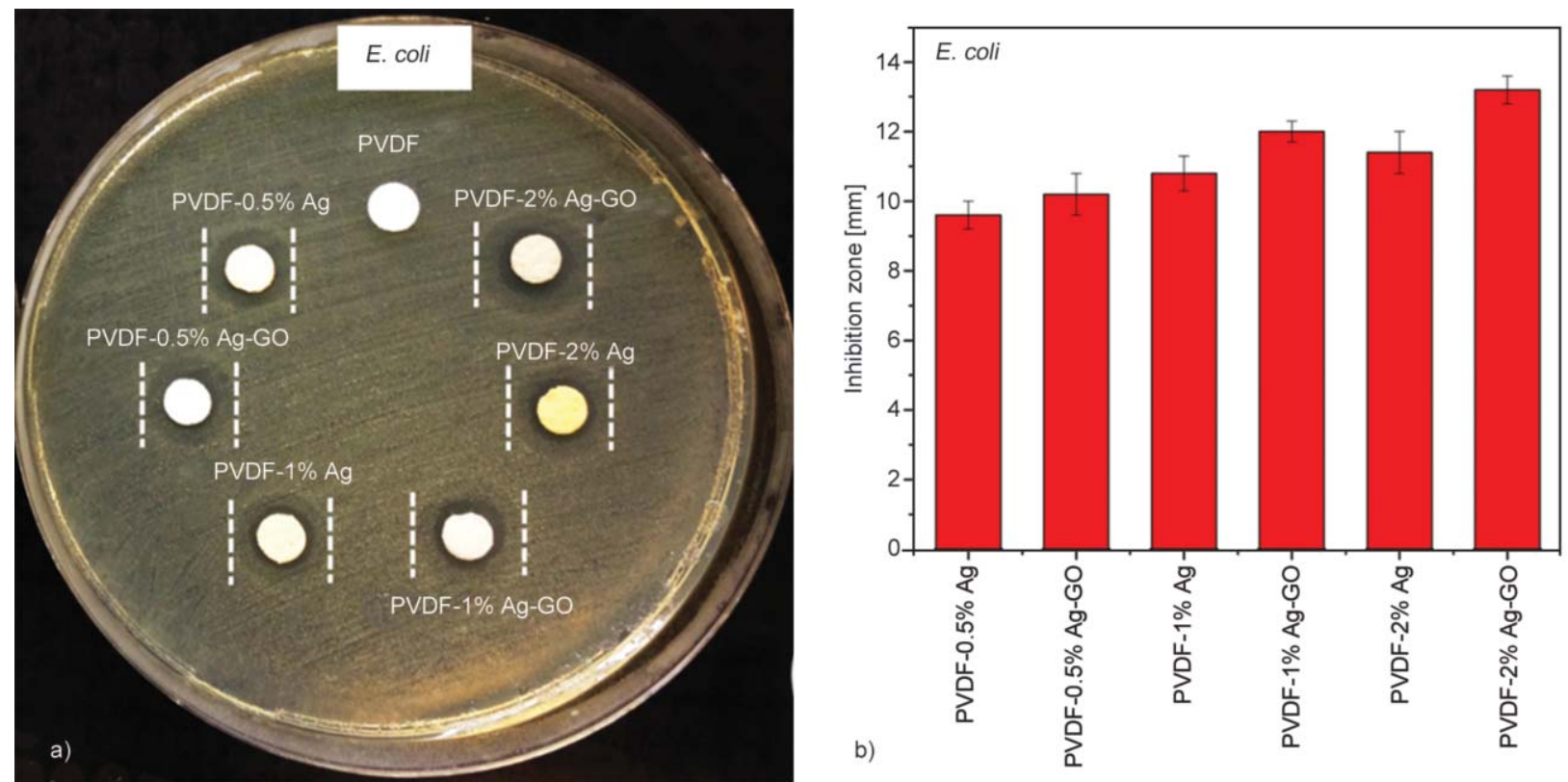

Figure 11. (a) Photograph and (b) diameter of the zone of inhibition of electrospun PVDF and its nanocomposite membranes exposed to E. coli

PVDF and its nanocomposite membranes. Apparently, pure PVDF membrane exhibits poor bactericidal effect against $E$. coli due to the absence of an inhibition zone on LB agar plate. The inhibition zone generally serves as an indicator for antibacterial activity. By adding $0.5 \% \mathrm{Ag}$ to PVDF, the inhibition zone with a diameter of $9.6 \mathrm{~mm}$ can be readily observed (Figure 11b). Furthermore, the zone diameter increases with increasing Ag content in the PVDF-Ag system. The PVDF-GO-Ag membranes exhibit larger zone diameter by hybridizing GO with $1 \% \mathrm{Ag}$ and $2 \% \mathrm{Ag}$ due to uniform dispersion of AgNPs as mentioned earlier. The zone diameter rises to $13.2 \mathrm{~mm}$ for the PVDF-2\% Ag-GO membrane. These results demonstrate that antibacterial activity of the PVDF$\mathrm{Ag}$ and PVDF-Ag-GO systems is dependent on the release of $\mathrm{Ag}^{+}$ions from the membranes. Furthermore, the incorporation of GO into PVDF-Ag system also prevents bacteria from attaching to the membrane surface. So the PVDF-1\% GO-2\% Ag membrane with higher Ag loading exhibits the best resistance against $E$. coli. It is noted that GO is anti-bacterial in nature because it can kill bacteria by cutting their cell walls with its sharp edges, wrap the bacteria as a blanket, or oxidize bacterial cellular components [80]. The cutting mechanism is known as the nano-knife effect. In this respect, GO cuts the cell membrane and causes the leakage of intracellular constituents, thereby leading to death of bacteria [ 80 , 81]. This effect is particularly more effective for $E$. coli with a single cell wall of peptidoglycan layer.
Accordingly, the incorporation of GO into PVDF$2 \% \mathrm{Ag}$ and PVDF-1\% Ag membranes further enhances their bactericidal activity against $E$. coli.

More importantly, AgNPs of the PVDF-Ag and PVDF-GO-Ag membranes play a crucial role in bactericidal activity. AgNPs with high surface area to volume ratio can attach to the bacterial cell membranes, then penetrate through cell membrane into the cytoplasm [82, 83]. Some studies reported that released silver ions from $\mathrm{AgNPs}$ tend to interact with the sulfur-containing compounds of bacteria. So $\mathrm{Ag}^{+}$ ions can interact with thiol groups of enzymes of DNA, thus disrupting the metabolic processes and affecting the DNA ability to replicate. These processes finally lead to damage or death of bacterial cells [84]. A recent study by Bondarenko et al. [85] demonstrated that there exists a synergistic effect between these two antibacterial activities. Direct cell-nanoparticle contact facilitates the release of silver ions from AgNPs, thereby enhancing the amount of cellular uptake of particle associated $\mathrm{Ag}^{+}$ion.

Figure 12a shows the agar plate cultured with Grampositive $S$. aureus and then contacted directly with pure PVDF and its nanocomposite membranes. It can be seen that the bacteria grow well around PVDF membrane. The addition of $0.5 \% \mathrm{Ag}$ to PVDF has little effect in resisting the bacterial attack. There is almost no zone of inhibition observed on the agar plate around this sample. However, the diameter of inhibition zone against $S$. aureus increases with the additions of $1 \% \mathrm{Ag}-2 \% \mathrm{Ag}$ and (1-2)\% Ag-GO fillers 

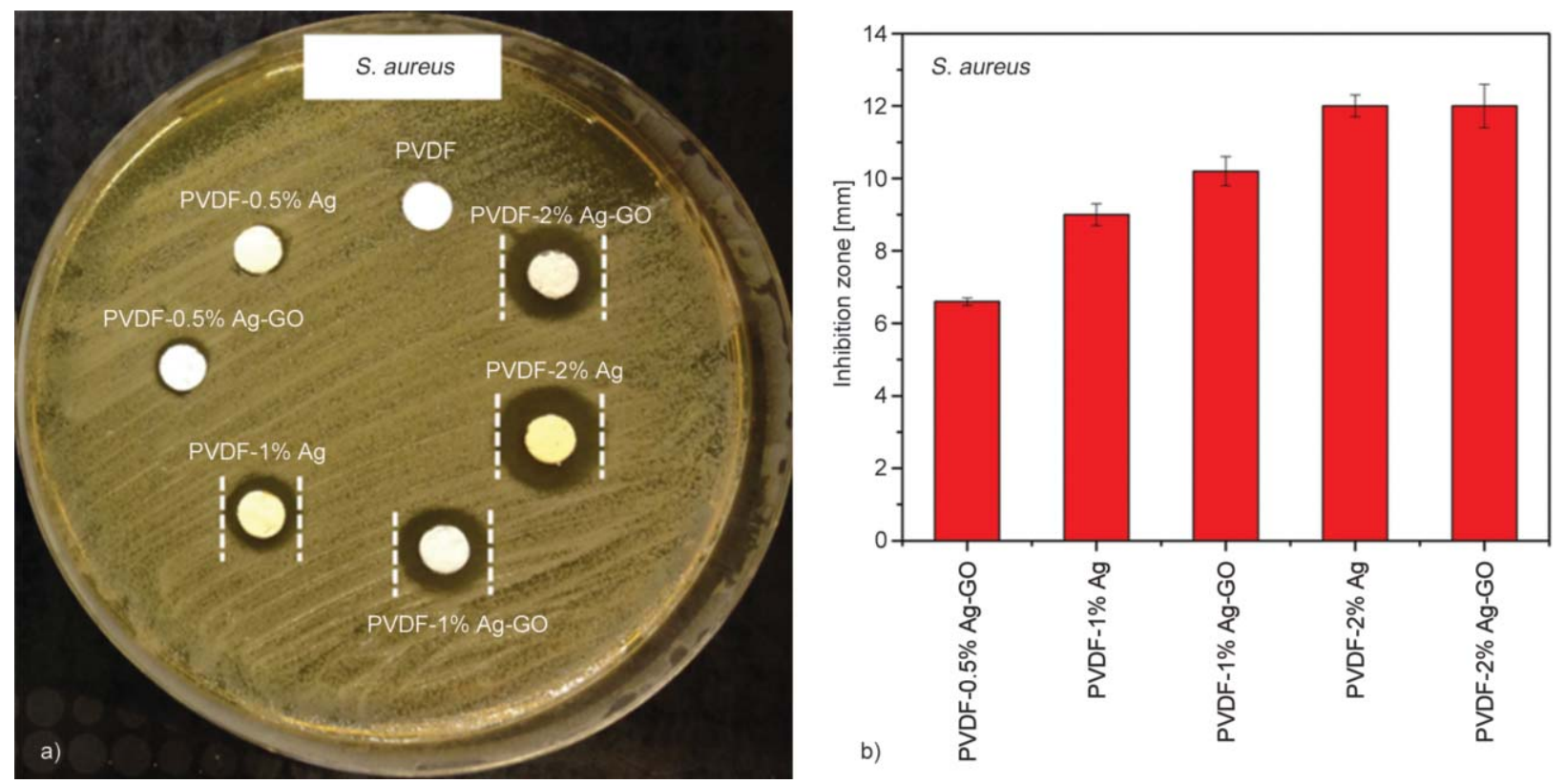

Figure 12. (a) Photograph and (b) diameter of the zone of inhibition of electrospun PVDF and its nanocomposite membranes exposed to S. aureus

to PVDF (Figure 12b). From the size of inhibition zones, PVDF-based nanocomposite membranes have a weaker bactericidal activity for Gram-positive $S$. aureus than for Gram-negative E. coli. In other words, Gram-positive bacteria are more resistant to the $\mathrm{Ag}^{+}$ attack than Gram-negative bacteria. This can be attributed to the difference in the cell wall structures of $S$. aureus and E. coli. Gram-positive bacteria exhibit a thick cell wall having many peptidoglycan layers interspaced with teichoic acid [86]. Therefore, such a thick cell wall can serve as a barrier for the penetration of $\mathrm{Ag}^{+}$ions into the cytoplasm. However, Gram-negative bacteria with a single cell wall of peptidoglycan layer are more susceptible to the $\mathrm{Ag}^{+}$ ions attack. The $\mathrm{Ag}^{+}$ions can readily penetrate a thinner peptidoglycan layer of $E$. coli, leading to more destruction of respiratory proteins and disruption of DNA replication.

\section{Conclusions}

We have fabricated electrospun PVDF-(0.5-2)\% Ag and PVDF-(0.5-2)\% Ag-1\% GO nanocomposite membranes with antifouling and antibacterial properties. Introduction of AgNPs and GO into PVDF membranes leads to the improvement in membrane wetting, tensile strength and elastic modulus, water permeability, antifouling property, and antibacterial resistance. Comparing with pristine PVDF mat, PVDF-2\% Ag-GO composite membranes exhibit high water flux recovery ratio of $93.7 \%$, low irreversible fouling ratio of $6 \%$, and large zone of inhibition against both $E$. coli and $S$. aureus strains. These results bring new perspectives for the development of novel PVDF-based nanocomposite membranes with excellent anti-biofouling properties for water purification and disinfection applications.

\section{Acknowledgements}

Liu C. and Shen J. contributed equally. This work was supported by the Applied Research Grant (No. 9667126), City University of Hong Kong, Shenzhen Science and Technology Project Grant (JCYJ20150630145302228), China, and Shenzhen Knowledge Innovation Program of Basic Research Items of Guangdong Province (JCYJ20140414090541811), China.

\section{References}

[1] Lalia B. S., Kochkodan V., Hashaikeh R., Hilal N.: A review on membrane fabrication: Structure, properties and performance relationship. Desalination, 326, 7795 (2013).

https://doi.org/10.1016/j.desal.2013.06.016

[2] Drioli E., Ali A., Macedonio F.: Membrane distillation: Recent developments and perspectives. Desalination, 356, 56-84 (2015).

https://doi.org/10.1016/j.desal.2014.10.028

[3] Meng Y. Z., Tjong S. C., Hay A. S., Wang S. J.: Synthesis and proton conductivities of phosphonic acid containing poly-(arylene ether)s. Journal of Polymer Science Part A: Polymer Chemistry, 39, 3218-3226 (2001).

https://doi.org/10.1002/pola.1304 
[4] Marchese J., Ponce M., Ochoa N. A., Prádanos P., Palacio L., Hernández A.: Fouling behaviour of polyethersulfone UF membranes made with different PVP. Journal of Membrane Science, 211, 1-11 (2003).

https://doi.org/10.1016/S0376-7388(02)00260-0

[5] Meng Y. Z., Hay A. S., Jian X. G., Tjong S. C.: Synthesis and properties of poly(aryl ether sulfone)s containing the phthalazinone moiety. Journal of Applied Polymer Science, 68, 137-143 (1998).

https://doi.org/10.1002/(SICI)10974628(19980404)68:1<137::AID-APP15>3.0.CO;2-Y

[6] Nguyen T., Roddick F. A., Fan L.: Biofouling of water treatment membranes: A review of the underlying causes, monitoring techniques and control measures. Membranes, 2, 804-840 (2012).

https://doi.org/10.3390/membranes2040804

[7] Amy G.: Fundamental understanding of organic matter fouling of membranes. Desalination, 231, 44-51 (2008). https://doi.org/10.1016/j.desal.2007.11.037

[8] Wang L., Miao R., Wang X., Lv Y., Meng X., Yang Y., Huang D., Feng L., Liu Z., Ju K: Fouling behavior of typical organic foulants in polyvinylidene fluoride ultrafiltration membranes: Characterization from microforces. Environmental Science and Technology, 47, 3708-3714 (2013). https://doi.org/10.1021/es4004119

[9] Akashi N., Kuroda S.: Preparation and characterization of protein A-immobilized PVDF and PES membranes. Express Polymer Letters, 9, 2-13 (2015). https://doi.org/10.3144/expresspolymlett.2015.2

[10] Rana D., Matsuura T.: Surface modifications for antifouling membranes. Chemical Reviews, 110, 24482471 (2010). https://doi.org/10.1021/cr800208y

[11] Martins P., Lopes A. C., Lanceros-Mendez S.: Electroactive phases of poly(vinylidene fluoride): Determination, processing and applications. Progress in Polymer Science, 39, 683-706 (2014).

https://doi.org/10.1016/j.progpolymsci.2013.07.006

[12] Ribeiro C., Sencadas V., Correia D. M., Lanceros-Méndez S.: Piezoelectric polymers as biomaterials for tissue engineering applications. Colloids and Surfaces B: Biointerfaces, 136, 46-55 (2015). https://doi.org/10.1016/j.colsurfb.2015.08.043

[13] Tjong S. C., Liang G. D.: Electrical properties of lowdensity polyethylene/ZnO nanocomposites. Materials Chemistry and Physics, 100, 1-5 (2006). https://doi.org/10.1016/j.matchemphys.2005.11.029

[14] Tjong S. C., Bao S. P.: Fracture toughness of high density polyethylene/SEBS- $g$-MA/montmorillonite nanocomposites. Composites Science and Technology, 67, 314-323 (2007).

https://doi.org/10.1016/j.compscitech.2006.08.006
[15] Liang G. D., Bao S. P., Tjong S. C.: Microstructure and properties of polypropylene composites filled with silver and carbon nanotube nanoparticles prepared by melt-compounding. Materials Science and Engineering: B, 142, 55-61 (2007). https://doi.org/10.1016/j.mseb.2007.06.028

[16] Bao S. P., Liang G. D., Tjong S. C.: Effect of mechanical stretching on electrical conductivity and positive temperature coefficient characteristics of poly(vinylidene fluoride)/carbon nanofiber composites prepared by non-solvent precipitation. Carbon, 49, 1758-1768 (2011).

https://doi.org/10.1016/j.carbon.2010.12.062

[17] Zheng G. P., Jiang Z. Y., Han Z., Yan J. H.: Mechanical and electro-mechanical properties of three-dimensional nanoporous graphene-poly(vinylidene fluoride) composites. Express Polymer Letters, 10, 730-741 (2016). https://doi.org/10.3144/expresspolymlett.2016.67

[18] Tsonos C., Pandis C., Soin N., Sakellari D., Myrovali E., Kripotou S., Kanapitsas A., Siores E.: Multifunctional nanocomposites of poly(vinylidene fluoride) reinforced by carbon nanotubes and magnetite nanoparticles. Express Polymer Letters, 9, 1104-1118 (2015). https://doi.org/10.3144/expresspolymlett.2015.99

[19] Meng Y. Z., Tjong S. C.: Rheology and morphology of compatibilized polyamide 6 blends containing liquid crystalline copolyesters. Polymer, 39, 99-107 (1998). https://doi.org/10.1016/S0032-3861(97)00218-8

[20] Tjong S. C., Yeager E.: ESCA and SIMS studies of the passive film on iron. Journal of the Electrochemical Society, 128, 2251-2254 (1981).

https://doi.org/10.1149/1.2127229

[21] Tjong S. C., Hoffman R. W., Yeager E. B.: Electron and ion spectroscopic studies of the passive film on ironchromium alloys. Journal of the Electrochemical Society, 129, 1662-1668 (1982).

https://doi.org/10.1149/1.2124232

[22] Li J-H., Shao X-S., Zhou Q., Li M-Z., Zhang Q-Q.: The double effects of silver nanoparticles on the PVDF membrane: Surface hydrophilicity and antifouling performance. Applied Surface Science, 265, 663-670 (2013). https://doi.org/10.1016/j.apsusc.2012.11.072

[23] Qin A., Li X., Zhao X., Liu D., He C.: Preparation and characterization of nano-chitin whisker reinforced PVDF membrane with excellent antifouling property. Journal of Membrane Science, 480, 1-10 (2015). https://doi.org/10.1016/j.memsci.2015.01.035

[24] Zhao C., Xu X., Chen J., Wang G., Yang F.: Highly effective antifouling performance of PVDF/graphene oxide composite membrane in membrane bioreactor (MBR) system. Desalination, 340, 59-66 (2014). https://doi.org/10.1016/j.desal.2014.02.022 
[25] Lopes A. C., Carabineiro S. A. C., Pereira M. F., Botelho G., Lanceros-Méndez S.: Nanoparticle size and concentration dependence of the electroactive phase content and electrical and optical properties of $\mathrm{Ag} / \mathrm{poly}$ (vinylidene fluoride) composites. ChemPhysChem, 14, 1926-1933 (2013).

https://doi.org/10.1002/cphc.201300174

[26] Zinadini S., Zinatizadeh A. A., Rahimi M., Vatanpour V., Zangeneh H.: Preparation of a novel antifouling mixed matrix PES membrane by embedding graphene oxide nanoplates. Journal of Membrane Science, 453, 292 301 (2014).

https://doi.org/10.1016/j.memsci.2013.10.070

[27] Shukla A. K., Alam J., Alhoshan M., Dass L. A., Muthumareeswaran M. R.: Development of a nanocomposite ultrafiltration membrane based on polyphenylsulfone blended with graphene oxide. Scientific Reports, 7, 41976/1-41976/12 (2017).

https://doi.org/10.1038/srep41976

[28] Greiner A., Wendorff J. H.: Electrospinning: A fascinating method for the preparation of ultrathin fibers. Angewandte Chemie International Edition, 46, 5670-5703 (2007). https://doi.org/10.1002/anie.200604646

[29] Mokhena T. C., Jacobs V., Luyt A. S.: A review on electrospun bio-based polymers for water treatment. Express Polymer Letters, 9, 839-880 (2015).

https://doi.org/10.3144/expresspolymlett.2015.79

[30] Ribeiro C., Sencadas V., Ribelles J. L. G., LancerosMéndez S.: Influence of processing conditions on polymorphism and nanofiber morphology of electroactive poly(vinylidene fluoride) electrospun membranes. Soft Materials, 8, 274-287 (2010).

https://doi.org/10.1080/1539445X.2010.495630

[31] Shen Y., Chen L., Jiang S., Ding Y., Xu W., Hou H.: Electrospun nanofiber reinforced all-organic PVDF/PI tough composites and their dielectric permittivity. Materials Letters, 160, 515-517 (2015).

https://doi.org/10.1016/j.matlet.2015.08.019

[32] Agarwal S., Jiang S.: Nanofibers and electrospinning. in 'Encyclopedia of polymeric nanomaterials' (eds.: Kobayashi S., Müllen K.) Springer, Berlin, 1-15 (2015). https://doi.org/10.1007/978-3-642-36199-9 370-1

[33] Gopal R., Kaur S., Ma Z., Chan C., Ramakrishna S., Matsuura T.: Electrospun nanofibrous filtration membrane. Journal of Membrane Science, 281, 581-586 (2006).

https://doi.org/10.1016/j.memsci.2006.04.026

[34] Jang W., Yun J., Jeon K., Byun H.: PVDF/graphene oxide hybrid membranes via electrospinning for water treatment applications. RSC Advances, 5, 46711-46717 (2015).

https://doi.org/10.1039/c5ra04439a
[35] Dobosz K. M., Kuo-Leblanc C. A., Martin T. J., Schiffman J. D.: Ultrafiltration membranes enhanced with electrospun nanofibers exhibit improved flux and fouling resistance. Industrial and Engineering Chemical Research, 56, 5724-5733 (2017).

https://doi.org/10.1021/acs.iecr.7b00631

[36] Viswanath V., Maity S., Bochinski J. R., Clarke L. I., Gorga R. E.: Enhanced crystallinity of polymer nanofibers without loss of nanofibrous morphology via heterogeneous photothermal annealin. Macromolecules, 49, 9484-9492 (2016). https://doi.org/10.1021/acs.macromol.6b01655

[37] Ramaswamy S., Clarke L. I., Gorga R. E.: Morphological, mechanical, and electrical properties as a function of thermal bonding in electrospun nanocomposites. Polymer, 52, 3183-3189 (2011). https://doi.org/10.1016/j.polymer.2011.05.023

[38] Bauer A., Kirby W., Sherris J., Turck M.: Antibiotic susceptibility testing by a standardized single disc method. American Journal of Clinical Pathology, 45, 493-496 (1966).

[39] Spilarewicz-Stanek K., Kisielewska A., Ginter J., Bałuszyńska K., Piwoński I.: Elucidation of the function of oxygen moieties on graphene oxide and reduced graphene oxide in the nucleation and growth of silver nanoparticles. RSC Advances, 6, 60056-60067 (2016). https://doi.org/10.1039/c6ra10483e

[40] Lu G., Mao S., Park S., Ruoff R. S., Chen J.: Facile, noncovalent decoration of graphene oxide sheets with nanocrystals. Nano Research, 2, 192-100 (2009). https://doi.org/10.1007/s12274-009-9017-8

[41] Xu C., Wang X.: Fabrication of flexible metal-nanoparticle films using graphene oxide sheets as substrates. Small, 5, 2212-2217 (2009). https://doi.org/10.1002/smll.200900548

[42] He Y., Cui H.: Synthesis of highly chemiluminescent graphene oxide/silver nanoparticle nano-composites and their analytical applications. Journal of Materials Chemistry, 22, 9086-9091 (2012). https://doi.org/10.1039/c2jm16028e

[43] Yang Y-K., He C-E., He W-J., Yu L-J., Peng R-G., Xie X-L., Wang X-B., Mai Y-W.: Reduction of silver nanoparticles onto graphene oxide nanosheets with $N, N$-dimethylformamide and SERS activities of GO/Ag composites. Journal of Nanoparticle Research, 13, 55715581 (2011). https://doi.org/10.1007/s11051-011-0550-5

[44] He L. X., Tjong S. C.: Facile synthesis of silver-decorated reduced graphene oxide as a hybrid filler material for electrically conductive polymer composites. RSC Advances, 5, 15070-15076 (2015). https://doi.org/10.1039/c5ra00257e 
[45] Zhou X., Huang X., Qi X., Wu S., Xue C., Boey F. Y. C., Yan Q., Chen P., Zhang H.: In situ synthesis of metal nanoparticles on single-layer graphene oxide and reduced graphene oxide surfaces. Journal of Physical Chemistry C, 113, 10842-10846 (2009).

https://doi.org/10.1021/jp903821n

[46] Pasricha R., Gupta S., Srivastava A. K.: A facile and novel synthesis of Ag-graphene-based nanocomposites. Small, 5, 2253-2259 (2009).

https://doi.org/10.1002/smll.200900726

[47] Kim J. R., Choi S. W., Jo S. M., Lee W. S., Kim B. C.: Electrospun PVdF-based fibrous polymer electrolytes for lithium ion polymer batteries. Electrochimica Acta 50, 69-75 (2004).

https://doi.org/10.1016/j.electacta.2004.07.014

[48] Hwang K., Kwon B., Byun H.: Preparation of PVdF nanofiber membranes by electrospinning and their use as secondary battery separators. Journal of Membrane Science, 378, 111-116 (2011).

https://doi.org/10.1016/j.memsci.2011.06.005

[49] Correia D. M., Ribeiro C., Sencadas V., Botelho G., Carabineiro S. A., Ribelles J. L., Lanceros-Méndez S.: Influence of oxygen plasma treatment parameters on poly(vinylidene fluoride) electrospun fiber mats wettability. Progress in Organic Coatings, 85, 151-158 (2015). https://doi.org/10.1016/j.porgcoat.2015.03.019

[50] He F., Fan J., Chan L. H.: Preparation and characterization of electrospun poly(vinylidene fluoride)/poly (methyl methacrylate) membrane. High Performance Polymers, 26, 817-825 (2014).

https://doi.org/10.1177/0954008314531030

[51] Drew C., Wang X., Samuelson L. A., Kumar J.: The effect of viscosity and filler on electrospun fiber morphology. Journal of Macromolecular Science Part A: Pure and Applied Chemistry, 40, 1415-1422 (2003). https://doi.org/10.1081/MA-120025320

[52] Xia X., Ni M.: Preparation of poly(vinylidene fluoride) membranes with graphene oxide addition for natural organic matter removal. Journal of Membrane Science, 473, 54-62 (2015).

https://doi.org/10.1016/j.memsci.2014.09.018

[53] Matabola K. P., Moutloali R. M.: The influence of electrospinning parameters on the morphology and diameter of poly(vinyledene fluoride) nanofibers - effect of sodium chloride. Journal of Materials Science, 48, 5475-5482 (2013).

https://doi.org/10.1007/s10853-013-7341-6

[54] Heikkila P., Harlin A.: Electrospinning of polyacrylonitrile (PAN) solution: Effect of conductive additive and filler on the process. Express Polymer Letters, 3, 437 445 (2009).

https://doi.org/10.3144/expresspolymlett.2009.53

[55] Issa A. A., Al-Maadeed M. A., Luyt A. S., Ponnamma D., Hassan M. K.: Physico-mechanical, dielectric, and piezoelectric properties of PVDF electrospun mats containing silver nanoparticles. Journal of Carbon Research, 3, 30/1-30/16 (2017).

https://doi.org/10.3390/c3040030
[56] El Achaby M., Arrakhiz F. Z., Vaudreuil S., Essassi E. M., Qaiss A.: Piezoelectric $\beta$-polymorph formation and properties enhancement in graphene oxide - PVDF nanocomposite films. Applied Surface Science, 258, 7668-7677 (2012).

https://doi.org/10.1016/j.apsusc.2012.04.118

[57] Manna S., Batabyal S. K., Nandi A. K.: Preparation and characterization of silver-poly(vinylidene fluoride) nanocomposites: Formation of piezoelectric polymorph of poly(vinylidene fluoride). Journal of Physical Chemistry $\mathrm{B}, \mathbf{1 1 0}, 12318-12326$ (2005).

https://doi.org/10.1021/jp061445y

[58] Lin J., Ding B., Yu J., Hsieh Y.: Direct fabrication of highly nanoporous polystyrene fibers via electrospinning. Applied Materials and Interfaces, 2, 521-528 (2010). https://doi.org/10.1021/am900736h

[59] Casper C. L., Stephens J. S., Tassi N. G., Chase D. B., Rabolt J. F.: Controlling surface morphology of electrospun polystyrene fibers: Effect of humidity and molecular weight in the electrospinning process. Macromolecules, 37, 573-578 (2007).

https://doi.org/10.1021/ma0351975

[60] El Mohajir B-E., Heymans N.: Changes in structural and mechanical behaviour of PVDF with processing and thermomechanical treatments. 1. Change in structure. Polymer, 42, 5661-5667 (2001).

https://doi.org/10.1016/S0032-3861(01)00064-7

[61] Sundaray B., Bossard F., Lati P., Orgéas L., Sanchez J. Y., Lepretre J. C.: Unusual process-induced curl and shrinkage of electrospun PVDF membranes. Polymer, 54, 4588-4593 (2013). https://doi.org/10.1016/j.polymer.2013.05.049

[62] An N., Liu S., Fang C., Yu R., Zhou X., Cheng Y.: Preparation and properties of $\beta$-phase graphene oxide/ PVDF composite films. Journal of Applied Polymer Science, 132, 41577/1-41577/8 (2015).

https://doi.org/10.1002/app.41577

[63] Bao C., Guo Y., Song L., Hu Y.: Poly(vinyl alcohol) nanocomposites based on graphene and graphite oxide: A comparative investigation of property and mechanism. Journal of Materials Chemistry, 21, 13942-13950 (2011). https://doi.org/10.1039/C1JM11662B

[64] Tjong S. C., Liu S. L., Li R. K. Y.: Mechanical properties of injection moulded blends of polypropylene with thermotropic liquid crystalline polymer. Journal of Materials Science, 31, 479-484 (1996).

https://doi.org/10.1007/BF01139167

[65] Tjong S. C., Meng Y. Z.: Morphology and mechanical characteristics of compatibilized polyamide 6-liquid crystalline polymer composites. Polymer, 38, 46094615 (1997).

https://doi.org/10.1016/S0032-3861(96)01082-8 
[66] Zhao Z., Li J., Yuan X., Li X., Zhang Y., Sheng J.: Preparation and properties of electrospun poly(vinylidene fluoride) membranes. Journal of Applied Polymer Science, 97, 466-474 (2005).

https://doi.org/10.1002/app.21762

[67] Lee C., Wei X., Kysar J. W., Hone J.: Measurement of the elastic properties and intrinsic strength of monolayer graphene. Science, 321, 385-388 (2008).

https://doi.org/10.1126/science.1157996

[68] Liu L., Zhang J., Zhao J., Liu F.: Mechanical properties of graphene oxides. Nanoscale, 4, 5910-5916 (2012). https://doi.org/10.1039/c2nr31164j

[69] Suk J. W., Piner R. D., An J., Ruoff R. S.: Mechanical properties of monolayer graphene oxide. ACS Nano, 4, 6557-6564 (2010).

https://doi.org/10.1021/nn101781v

[70] Liao X., Ye W., Chen L., Jiang S., Wang G., Zhang L., Hou H.: Flexible hdC-G reinforced polyimide composites with high dielectric permittivity. Composites Part A: Applied Science and Manufacturing, 101, 50-58 (2017). https://doi.org/10.1016/j.compositesa.2017.06.011

[71] Shah D., Maiti P., Gunn E., Schmidt D. F., Jiang D. D., Batt C. A., Giannelis E. P.: Dramatic enhancements in toughness of polyvinylidene fluoride nanocomposites via nanoclay-directed crystal structure and morphology. Advanced Materials, 16, 1173-1177 (2004). https://doi.org/10.1002/adma.200306355

[72] Cho D., Chen S., Jeong Y., Joo Y. L.: Surface hydroproperties of electrospun fiber mats. Fibers and Polymers, 16, 1578-1586 (2015). https://doi.org/10.1007/s12221-015-5258-1

[73] Wang Z., Crandall C., Sahadevan S., Menkhaus T. J., Fong H.: Microfiltration performance of electrospun nanofiber membranes with varied fiber diameters and different membrane porosities and thicknesses. Polymer, 114, 64-72 (2017).

https://doi.org/10.1016/j.polymer.2017.02.084

[74] Lee J-W., Jung J., Cho Y. H., Yadav S. K., Baek K. Y., Park H. B., Hong S. M., Koo C. M.: Fouling-tolerant nanofibrous polymer membranes for water treatment. ACS Applied Materials and Interfaces, 6, 14600-14607 (2014). https://doi.org/10.1021/am503874b

[75] Pal A., Dey T. K., Debnath A. K., Bhushan B., Sahu A. K., Bindal R. C., Kar S.: Mixed-matrix membranes with enhanced antifouling activity: Probing the surface-tailoring potential of Tiron and chromotropic acid for nano- $\mathrm{TiO}_{2}$. Royal Society Open Science, 4, 170368/1170368/22 (2017).

https://doi.org/10.1098/rsos. 170368

[76] Iorhemen O. T., Hamza R. A., Tay J. H.: Membrane bioreactor (MBR) technology for wastewater treatment and reclamation: Membrane fouling. Membranes, 6, 33/1-33/29 (2016). https://doi.org/10.3390/membranes6020033
[77] Whitfield G. B., Marmont L. S., Howell P. L.: Enzymatic modifications of exopolysaccharides enhance bacterial persistence. Frontiers in Microbiology, 6, 471/1-471/21 (2015). https://doi.org/10.3389/fmicb.2015.00471

[78] Vanysacker L., Declerck P., Bilad M. R., Vankelecom I. F.: Biofouling on microfiltration membranes in MBRs: Role of membrane type and microbial community. Journal of Membrane Science, 453, 394-401 (2014). https://doi.org/10.1016/j.memsci.2013.11.024

[79] Monerris M., Broglia M., Yslas I., Barbero C., Rivarola C.: Antibacterial polymeric nanocomposites synthesized by in-situ photoreduction of silver ions without additives inside biocompatible hydrogel matrices based on $N$-isopropylacrylamide and derivatives. Express Polymer Letters, 11, 946-962 (2017). https://doi.org/10.3144/expresspolymlett.2017.91

[80] Zou X., Zhang L., Wang Z., Luo Y.: Mechanisms of the antimicrobial activities of graphene materials. Journal of the American Chemical Society, 138, 2064-2077 (2016). https://doi.org/10.1021/jacs.5b11411

[81] Tegou E., Magana M., Katsogridaki A. E., Ionnidis A., Raptis V., Jordan S., Chatzipanagiotou S., Chatzandroulis S., Ornelas C., Tegos G. P.: Terms of endearment: Bacteria meet graphene nanosurfaces. Biomaterials, 89, 3855 (2016). https://doi.org/10.1016/j.biomaterials.2016.02.030

[82] Morones J. L., Elichiguerra A., Camacho K., Holt J. B., Kouri J. T., Ramírez M. Y., Yacaman M. J.: The bactericidal effect of silver nanoparticles. Nanotechnology, 16, 2346-2353 (2005). https://doi.org/10.1088/0957-4484/16/10/059

[83] Gogoi S. K., Gopinath P., Paul A., Ramesh A., Ghosh S. S., Chattopadhyay A.: Green fluorescent protein-expressing Escherichia coli as a model system for investigating the antimicrobial activities of silver nanoparticles. Langmuir, 22, 9322-9328 (2006). https://doi.org/10.1021/la060661v

[84] Feng Q. L., Wu J., Chen G. Q., Cui F. Z., Kim T. N., Kim J. O.: A mechanistic study of the antibacterial effect of silver ions on Escherichia coli and Staphylococcus aureus. Journal of Biomedical Materials Research, 52, 662-668 (2000). https://doi.org/10.1002/10974636(20001215)52:4<662::AID-JBM10>3.0.CO;2-3

[85] Bondarenko O., Ivask A., Käkinen A., Kurvet I., Kahru A.: Particle-cell contact enhances antibacterial activity of silver nanoparticles. PLoS One, 8, e64060/1e64060/12 (2013). https://doi.org/10.1371/journal.pone.0064060

[86] van der Wal A., Norde W., Zehnder A. J. B., Lyklema J.: Determination of the total charge in the cell walls of Gram-positive bacteria. Colloids and Surfaces B: Biointerfaces, 9, 81-100 (1997). https://doi.org/10.1016/S0927-7765(96)01340-9 